\title{
Wage Rigidities in Western Germany? Microeconometric Evidence from the 1990s
}

\author{
by \\ Patrick A. Puhani* \\ SIAW, University of Sankt Gallen
}

June 2001

JEL classification: J31, J64

Keywords: wages, unemployment, rigidities, identification, Germany

Dr. Patrick A. Puhani

University of St. Gallen

SIAW, Room 129

Dufourstr. 48

CH-9000 St. Gallen

Switzerland

Phone: ++41 - 71- 2242341

Fax: $\quad++41-71-2242298$

E-Mail:_Patrick.Puhani@unisg.ch

\footnotetext{
*The author is also a Research Affiliate at the Center for Economic Policy Research (CEPR), London, UK, the Centre for European Economic Research (ZEW), Mannheim, Germany, a Research Fellow of the Institute for the Study of Labor (IZA), Bonn, Germany, and of the William Davidson Institute at the University of Michigan Business School, Ann Arbor, MI, U.S.A.
} 


\section{Non-Technical Summary}

The fact that in the 1980s and in the early 1990s wage inequality has increased significantly in the United States, but hardly, if at all, in Germany, is well-established empirically. Furthermore, there is convincing empirical evidence that the different experiences of the United States on the one hand and Germany on the other can be traced back to differences in supply and institutional factors. As to supply, the rise in wage inequality in the United States has substantially been driven by increasing returns to skills. Yet higher increases in the relative supply of skilled $v s$. low-skilled labour in Germany than in the U.S. have contributed to the ability of Germany to prevent wage inequality to rise to U.S. levels. As to institutional differences, there is empirical support for the hypothesis that the system of wage bargaining in Germany has prevented wages of low-skilled workers to fall to levels that would be justified by supply and demand developments. The existence of institutional barriers to greater wage dispersion at the lower end of the wage distribution raises the question of whether these barriers cause unemployment of less skilled workers in Germany.

In order to test the hypothesis that rising unemployment rates of the low-skilled in Europe are related to the development of wages of this group, I propose an empirical methodology which makes less restrictive identifying assumptions than some previous related studies. In this paper, a 'strong wage rigidity dynamic' is defined as a rising wage rate and a rising unemployment rate in a labour market (one may also call this case 'wage push', as the word 'rigidity' often implies that the wage does not change). A 'weak wage rigidity dynamic in a decreasing market' is defined as a constant wage rate and a rising unemployment rate. The analysis further distinguishes between rigidities related to average wage developments and those related to the wage structure (i.e. relative wage developments).

The proposed methodology could serve collective bargaining partners as an information tool in the form of a 'wage monitor'. With a large and detailed data set, one can give advice to collective bargaining partners as to whether (the lack of) recent developments in the wage structure have been warranted by market forces. Collective bargaining partners may pay special attention to sections of the labour market where wage behaviour has been identified as having been 'rigid' in the very recent past. 
In an application of my methodology to west German individual data from the German SocioEconomic Panel (GSOEP), I find that the west German wage structure exhibited no 'strong rigidities' between 1992 and 1998. However, 'weak wage rigidities in a decreasing market' are found for the characteristic young and for the characteristic white-collar worker: the ceteris paribus analysis demonstrates that these groups experienced an increase in the unemployment likelihood but no change in the wage relative to the 'average person'. What do my results suggest for the validity of Krugman's hypothesis that 'the European unemployment problem and the U.S. inequality problem are two sides of the same coin' (Krugman, 1994, p. 37), namely a fall in the relative demand for low-skilled workers? Krugman's hypothesis implies that - in the face of falling demand - inflexible wages for the low-skilled in Europe have been responsible for rising unemployment rates for this group. The evidence for western Germany in the 1990s demonstrates that this is only partly true: considering different dimensions of skill (e.g. age (experience), education, occupation, and others), I find that there has been no ceteris paribus fall in the relative demand for low-educated and blue-collar workers in western Germany in the 1990s. Hence, the comparatively stable wage structure with respect to low educational achievement and blue-collar occupation seems to have been justified by market forces. Support for Krugman's hypothesis, on the other hand, is provided by the finding that the west German wage structure did not respond to a negative relative demand shock for young workers (who have little labour market experience). This has led to a ceteris paribus increase in relative unemployment for this group.

Moreover, at a 'macroeconomic' level, one observes that average real wages as well as the average unemployment rate have risen in the 1990s. Thus, average wages have been 'strongly rigid' (as defined in this paper) during the observation period. 
Abstract: This paper investigates whether and in what sense the west German wage structure has been 'rigid' in the 1990s. To test the hypothesis that a rigid wage structure has been responsible for rising low-skilled unemployment, I propose a methodology which makes less restrictive identifying assumptions than some previous related work.

I find that the relative stability of educational wage premia was justified by market forces. However, relative wages did not respond to negative net demand shocks for young workers, as well as white-collar workers.

\section{Acknowledgement}

I thank the Centre for European Economic Research (ZEW), Mannheim, for letting me work with the full sample of the German Socio-Economic Panel.

I am grateful to Michael Lechner, Markus Frölich, Ruth Miquel, SIAW, University of Sankt Gallen, Rob Euwals, IZA, Bonn, and participants of the CEPR-IZA European Summer Symposium in Labour Economics 2001, Buch, Germany, and the Meeting of the Econometrics and Statistics Study Group of the Swiss Society for Economics and Statistics, University of Berne, Switzerland, for helpful comments.

All remaining errors are my own. 


\section{Introduction}

The fact that in the 1980s and in the early 1990s wage inequality has increased significantly in the United States, but hardly, if at all, in Germany, is well-established empirically (see e.g. Freeman and Katz, 1995; Nickell and Bell, 1995; 1996; OECD, 1996; Gottschalk and Smeeding, 1997; Katz and Autor, 1999; for international comparisons, and Abraham and Houseman, 1995; Steiner and Wagner, 1998; Fitzenberger, 1999; and Möller, 1999; for the west German case). Furthermore, there is convincing empirical evidence that the different experiences of the United States on the one hand and Germany on the other can be traced back to differences in supply and institutional factors. As to supply, the rise in wage inequality in the United States has substantially been driven by increasing returns to skills (Bound and Johnson, 1992; Katz and Murphy, 1992; Juhn, Murphy, and Pierce, 1993; Katz and Autor, 1999). Yet higher increases in the relative supply of skilled vs. low-skilled labour in Germany than in the U.S. have contributed to the ability of Germany to prevent wage inequality to rise to U.S. levels (Abraham and Houseman, 1995; Freeman and Schettkat, 1999). As to institutional differences, there is empirical support for the hypothesis that the system of wage bargaining in Germany has prevented wages of low-skilled workers to fall to levels that would be justified by supply and demand developments (Blau and Kahn, 1996; Büttner and Fitzenberger, 1998; Kahn, 2000).

The existence of institutional barriers to greater wage dispersion at the lower end of the wage distribution raises the question of whether these barriers cause unemployment of less skilled workers in Germany (Krugman's hypothesis, Krugman, 1994, p. 37). According to a simple labour market model with Marshallian demand and supply schedules, this should indeed be the case. However, it has to be shown empirically that the German wage structure is responsible for high unemployment. Econometric evidence on this issue is still rare and a debate on the appropriate methodology to investigate this topic is missing.

This paper investigates whether and in what sense the west German wage structure has been 'rigid' in the 1990s. To test the hypothesis that a rigid wage structure has been responsible for rising lowskilled unemployment, I propose a methodology which makes less restrictive identifying assumptions than some previous related work. Furthermore, rather than looking at only two or three skill groups, different dimensions of skill as well as other factors making labour heterogeneous are considered. My empirical results on the basis of the German Socio-Economic Panel show that the stability of the west German wage structure with respect to educational 
attainments was justified by market forces between 1992 and 1998. However, unemployment of young as well as white-collar workers increased above average, yet the west German wage structure did not respond to these developments.

The paper is structured as follows. Previous related studies and their methodologies are assessed in the following Section 2. Section 3 presents a brief theoretical outline and motivates the assumptions underlying the empirical analysis. Estimation results are presented and discussed in Section 4. Section 5 concludes.

\section{Previous Related Methodologies}

Econometric evidence for Germany on the subject of rigidities in the wage structure and their (un-) employment effects can be divided methodologically into three types of studies which are summarised in Table 1 and discussed in the following.

First, there is the methodology developed by Card, Kramarz, and Lemieux (1999) which has been applied to German data by Krueger and Pischke (1997) and in a slightly different version by Beissinger and Möller (1998). Key identifying assumptions of this approach are that (i) there are only labour demand, no supply shocks, (ii) the size of a labour demand shock in a given period for a type of labour (e.g. low-skilled) is linearly related to the wage position of this type of labour at the beginning of the period, and (iii) the elasticity of labour demand with respect to the own wage is negative. Given these assumptions (Beissinger and Möller 1998 need only use assumption (ii) of these), one can correlate initial wages (a proxy for relative demand shocks) with subsequent wage and employment changes over a population of heterogeneous types of labour. If the German unlike the U.S. wage structure is rigid with respect to adverse labour demand shocks for low-skilled labour, one would expect 1) a positive correlation between initial wages and wage changes in the United States but not so much in Germany, 2) no correlation between initial wage and employment changes in the United States but a positive one in Germany. The evidence presented by Krueger and Pischke (1997) concurs with statement 1), but rejects statement 2), because in both the United States and western Germany, there has been no link between initial wages and relative employment changes in the 1980s. This would mean that although the west German wage structure did not change much in the observation period, this did not have implications on the employment structure and could be justified by market forces. Beissinger and Möller (1998) find the same result for men, but not for women: there seems to be evidence for a rigidity in the female wage structure which has negative employment effects. 
The second type of methodology uses the cross-sectional variation of indices of union participation in wage setting across countries to estimate its effects on relative wages and employment-topopulation ratios of the low-skilled (Kahn, 2000). Key identifying assumptions of this method are (iii) the elasticity of labour demand with respect to the own wage is negative, (iv) differences in employment-to-population ratios between countries reflect differences in labour demand, not supply (as this can only partly be controlled for), (v) there are no unobserved country-specific factors which influence employment-to-population ratios or wages, and (vi) skill groups as measured are comparable between countries. If in particular these assumptions are met, 1) an observed positive correlation between union participation in wage setting and relative wages of the low-skilled and 2) an observed negative correlation between union participation in wage setting and relative employment-to-population ratios of the low-skilled can be interpreted as a causal negative impact of unions on low-skilled employment through excessive wage setting for this group. Kahn's (2000) inference is based on estimates with a cross-sectional dimension of 15 countries (including Germany and the United States). It turns out that in a significant number of the various specifications presented by the author, union participation both raises relative wage and lowers relative employment-to-population ratios of the low-skilled. Although western Germany is part of the sample, it is not immediately clear from Kahn's (2000) work what conclusions one would draw for the responsibility of German unions for the low employment rates of low-skilled Germans. The reason is that although union participation is fairly high in Germany as measured by various indices, it is not possible to infer from the presented results in Kahn (2000) whether western Germany is a representative observation for the empirical finding or whether is it more of an outlier.

As a third methodology, elasticities of substitution between skilled and low-skilled labour have been used to estimate which wage adjustments are necessary to reduce low-skilled unemployment in western Germany. Key identifying assumptions of this approach are that (vii) there is a stable relationship between relative wages and relative labour demand in the observation period, (viii) relative labour supply of different skill groups is constant, and (ix) the estimated elasticity of substitution between skilled and low-skilled labour is also relevant for a (possibly) out of sample prediction of relative wage changes. Under assumptions (vii) and (ix), one can calculate for any desired relative labour demand (employment) change the required relative wage change. If assumption (viii) is met, the induced employment changes will feed one-to-one into unemployment changes, because relative wage changes will only have relative demand, but no relative supply effects. Although there are several studies estimating elasticities of substitution between skilled 
and low-skilled labour in western Germany (e.g. Fitzroy and Funke, 1995; Entorf, 1996; Beissinger and Möller, 1998; Steiner and Wagner, 1997; Steiner and Mohr, 1998; Möller, 2000; Falk and Koebel, 2001), only Fitzenberger and Franz (1998; 2000) and Fitzenberger (1999) simulate required relative wage changes for an equalisation (or change) of unemployment rates of mediumand low-skilled workers. The estimates suggest a required increase in the wage ratio between these groups of between 5 and 7 per cent (Fitzenberger, 1999).

Hence, in sum, previous evidence is somewhat inconclusive both with respect to the methodology which should be applied and the empirical results. The aim in this paper is to investigate whether there is evidence for the hypothesis that relative wage developments in western Germany in the 1990s can be held responsible for rising low-skilled unemployment. For this to be the case, there should, for example, have occurred a negative net demand shock for the low skilled combined with wage setting behaviour which prevented relative wage losses for this group. To take this hypothesis to the data, my concept of 'wage rigidity' is related to the joint observation of wage and unemployment changes. A wage rate is called 'rigid' in this paper if it rises or stays constant, but unemployment rises simultaneously. This would indicate that the rising or constant wage rate has contributed to an increasing degree of quantity rationing in the labour market ( $c f$. Maddala, 1983, Chapter 10).

The question I ask is therefore similar to the one addressed by Krueger and Pischke (1997) and Beissinger and Möller (1998) using the Card, Kramarz, and Lemieux (1999) methodology. However, I argue that the hypothesis of 'wage rigidity' can be tested with less restrictive assumptions than the ones imposed in this previous work. In particular, my assumption (a) (see Section 3.1 and Table 1) is fulfilled if labour demand and supply schedules are 'downward' and 'upward' sloping, respectively, or, in case the labour supply schedule is backward bending, it must be less steep than the labour demand schedule and there must be no excess demand for labour. Assumption (a) can also be fulfilled in other cases, though. Although my assumption (a) and assumption (iii) implicitly made by Krueger and Pischke (1997) are not strictly nested, most labour economists would probably find it plausible that both of them are fulfilled. I also assume that (b) $\operatorname{sgn}\left(\Delta_{t}^{t+\tau} U(\mathbf{x})_{\text {total }}\right)=\operatorname{sgn}\left(\Delta_{t}^{t+\tau} U(\mathbf{x})_{\text {rigid wage rate }}\right) \quad \forall \mathbf{x}$, which means that the sign of the change in the total unemployment rate is equal to the sign of the change in the unemployment rate due to a rigid wage rate in all labour markets $\mathbf{x}$ (explained in more detail below). This assumption places restrictions on the 'frictional unemployment rate' which is not allowed to vary the observed unemployment rate exogenously. A condition similar to my assumption (b) must also be fulfilled 
to agree with the interpretation of the Krueger and Pischke (1997) and Beissinger and Möller (1998) studies. Beissinger and Möller (1998) must also make my assumption (a) implicitly. So if both assumptions (iii) and (a) are met, my other key identifying assumptions are less restrictive than the ones by Krueger and Piscke (1997) and Beissinger and Möller (1998), because my methodology works without imposing assumptions (i) or (ii).

The assumptions made by Kahn (2000), Fitzenberger and Franz (1998; 2000), Fitzenberger (1999) and mine are not nested. The cross-country nature of the data used in Kahn (2000) and the somewhat different question addressed by Fitzenberger and Franz (1998; 2000), and Fitzenberger (1999) can be expected to require other types of identifying assumptions.

In the following section, I outline the approach taken in this paper in detail. 
Table 1: (Micro-)Econometric Methodologies Applied to Study Wages and (Un-)Employment in Germany

\begin{tabular}{|c|c|c|c|c|}
\hline Study & Implicit Key Identifying Assumptions & Main Data Sets & Methodology & Key Findings \\
\hline $\begin{array}{l}\text { Krueger and } \\
\text { Pischke } \\
\text { (1997) }\end{array}$ & $\begin{array}{l}\text { (i) There are only labour demand, no supply shocks } \\
\text { (ii) The size of a labour demand shock in a given } \\
\text { period for a type of labour is linearly related to } \\
\text { the wage position of this type of labour at the } \\
\text { beginning of the period } \\
\text { (iii) The elasticity of labour demand with respect to } \\
\text { the own wage is negative } \\
\text { something similar to my assumption (b) }\end{array}$ & $\begin{array}{l}\text { Mikrozensus and } \\
\text { 'Qualification } \\
\text { and Careers } \\
\text { Survey' } \\
\text { 1979-1991 }\end{array}$ & $\begin{array}{l}\text { Estimation of correlation } \\
\text { between (1) labour } \\
\text { demand shocks and wage } \\
\text { changes and (2) labour } \\
\text { demand shocks and } \\
\text { employment-to } \\
\text { population changes }\end{array}$ & $\begin{array}{l}\text { The inflexibility of the wage structure } \\
\text { had no measurable effects on the } \\
\text { employment structure }\end{array}$ \\
\hline $\begin{array}{l}\text { Beissinger } \\
\text { and Möller } \\
(1998)\end{array}$ & $\begin{array}{l}\text { (ii) The size of a labour demand shock in a given } \\
\text { period for a type of labour is linearly related to } \\
\text { the wage position of this type of labour at the } \\
\text { beginning of the period } \\
\text { my assumption (a) } \\
\text { something similar to my assumption (b) }\end{array}$ & $\begin{array}{l}\text { IAB Beschäftig- } \\
\text { tenstichprobe } \\
1980-1990\end{array}$ & $\begin{array}{l}\text { Estimation of correlation } \\
\text { between (1) labour } \\
\text { demand shocks and wage } \\
\text { changes and (2) labour } \\
\text { demand shocks and } \\
\text { employment rates } \\
\text { (employment divided by } \\
\text { the labour force) }\end{array}$ & $\begin{array}{l}\text { The low flexibility of the male wage } \\
\text { structure had no measurable effects on } \\
\text { the male employment structure } \\
\text { The inflexibility of the female wage } \\
\text { structure had measurable effects on the } \\
\text { female employment structure }\end{array}$ \\
\hline Kahn (2000) & $\begin{array}{l}\text { (iii) The elasticity of labour demand with respect to } \\
\text { the own wage is negative } \\
\text { (iv) Differences in employment-to-population } \\
\text { ratios between countries reflect differences in } \\
\text { labour demand, not supply (as this can only } \\
\text { partly be controlled for) } \\
\text { (v) There are no unobserved country-specific } \\
\text { factors which influence employment-to- } \\
\text { population ratios or wages } \\
\text { (vi) Skill groups as measured are comparable } \\
\text { between countries }\end{array}$ & $\begin{array}{l}\text { 'International } \\
\text { Social Survey } \\
\text { Programme' data } \\
\text { on } 15 \text { OECD } \\
\text { countries } \\
\text { 1985-1994 }\end{array}$ & $\begin{array}{l}\text { Estimation of correlation } \\
\text { between (1) union } \\
\text { participation in wage } \\
\text { setting and wages of low- } \\
\text { skilled relative to } \\
\text { medium-skilled workers } \\
\text { and between (2) union } \\
\text { participation in wage } \\
\text { setting and employment- } \\
\text { to-population ratios of } \\
\text { low-skilled relative to } \\
\text { medium-skilled workers }\end{array}$ & $\begin{array}{l}\text { Cross-sectional country differences in } \\
\text { union participation show that unions } \\
\text { increase relative wages of the low- } \\
\text { skilled; negative relative employment } \\
\text { effects of unions for this group can only } \\
\text { be found for men } \\
\text { It is not mentioned in the paper in what } \\
\text { way the German data contribute to these } \\
\text { findings }\end{array}$ \\
\hline
\end{tabular}


Table 1: (Micro-)Econometric Methodologies Applied to Study Wages and (Un-)Employment in Germany (ctd.)

\begin{tabular}{|c|c|c|c|c|}
\hline Study & Implicit Key Identifying Assumptions & Main Data Sets & Methodology & Key Findings \\
\hline $\begin{array}{l}\text { Fitzenberger } \\
\text { and Franz } \\
(1998)\end{array}$ & $\begin{array}{l}\text { (vii) There is a stable relationship between relative } \\
\text { wages and relative labour demand in the } \\
\text { observation period } \\
\text { (viii) The labour supply ratio of medium- over low- } \\
\text { skilled workers is constant in the observation } \\
\text { period } \\
\text { (ix) The estimated elasticity of substitution is } \\
\text { relevant for a potential out of sample prediction } \\
\text { of relative employment changes } \\
\text { something similar to my assumption (b) }\end{array}$ & $\begin{array}{l}\text { IAB Beschäftig- } \\
\text { tenstichprobe } \\
\text { (males only) } \\
1975-1990\end{array}$ & $\begin{array}{l}\text { Estimation of elasticity of } \\
\text { substitution between low- } \\
\text { and medium-skilled } \\
\text { workers }\end{array}$ & $\begin{array}{l}\text { To equalise unemployment rates of } \\
\text { medium- and low-skilled workers, the } \\
\text { wage ratio between these groups would } \\
\text { have to grow by } 15 \text { per cent }\end{array}$ \\
\hline $\begin{array}{l}\text { Fitzenberger } \\
\text { (1999) }\end{array}$ & As in Fitzenberger and Franz (1998) & $\begin{array}{l}\text { IAB Beschäftig- } \\
\text { tenstichprobe } \\
1975-1990\end{array}$ & $\begin{array}{l}\text { Similar to Fitzenberger } \\
\text { and Franz (1998) }\end{array}$ & $\begin{array}{l}\text { To equalise unemployment rates of } \\
\text { medium- and low-skilled workers, the } \\
\text { wage ratio between these groups would } \\
\text { have to grow by about } 5 \text { to } 6.6 \text { per cent }\end{array}$ \\
\hline This study & $\begin{array}{l}\text { (a) } D_{W} \times S-D \times S_{W}<0 \\
\text { (b) } \operatorname{sgn}\left(\Delta_{t}^{t+\tau} U(\mathbf{x})_{\text {total }}\right)=\operatorname{sgn}\left(\Delta_{t}^{++\tau} U(\mathbf{x})_{\text {rigid wage rate }}\right) \quad \forall \mathbf{x}\end{array}$ & $\begin{array}{l}\text { German Socio- } \\
\text { Economic Panel } \\
1992 \text { and } 1998\end{array}$ & $\begin{array}{l}\text { Comparison of wage and } \\
\text { unemployment changes } \\
\text { associated with labour } \\
\text { market characteristics }\end{array}$ & $\begin{array}{l}\text { The west German wage structure has } \\
\text { been 'weakly rigid' with respect to } \\
\text { relative unemployment increases of } \\
\text { young workers and males }\end{array}$ \\
\hline
\end{tabular}

Notes: $D$ and $S$ denote the labour demand and supply functions, respectively. The index $W$ denotes the derivative with respect to the wage. A discussion of assumptions (a) and (b) is provided in Section 3.1. It is fulfilled if labour demand and labour supply schedules are 'downward' and 'upward' sloping, respectively, but also in other cases. Virtually all previous studies must impose something similar to my assumption (b) to make the interpretation of their results valid. The only potential exception is Kahn's (2000) study, if the attempt to control for factors influencing market frictions is successful. My assumption (a) and assumption (iii) implicitly made by Krueger and Pischke (1997) and Khan (2000) are not strictly nested. However, assumptions (a) and (iii) would probably be accepted as plausible by most labour economists. In this case, my assumptions would be less restrictive than the ones by Krueger and Piscke (1997) and Beissinger and Möller (1998), as I do not need to make assumptions (i) and (ii). 


\section{Econometric Considerations}

The motivation for my work is to show which information one can retrieve on wage rigidities under minimal assumptions by merely observing the signs of the wage and unemployment changes for heterogeneous types of workers. In the model presented in Section 3.1, unemployment changes are seen as changes in quantity rationing due to inflexible prices (wages) ( $c f$. Maddala, 1983, Chapter 10). Due to the potential existence of other types of unemployment (termed 'frictional' unemployment), I only attempt to identify changes in (rather than levels of) wage rigidities ('wage rigidity dynamics'). By using only the information on the change in the wage and unemployment rate in a labour market between two time periods $t$ and $t+\tau$, I do not make any statement on the 'appropriateness' of the wage distribution at period $t$. Thus I am agnostic about whether wages were too high or too low at time $t$ and restrict myself to asking whether, for example, there was a lack of wage rate change in the face of rising unemployment between periods $t$ and $t+\tau$. The information I identify this way can be very useful, though, as it can serve as an information tool for collective bargaining partners, when undesired unemployment changes have occurred for some types of labour between times $t$ and $t+\tau$.

Identifying whether wages were too high at any time $t$ would require different assumptions than the ones I make. For example, one could assume that 'frictional' unemployment has the same level for all types of heterogeneous labour. Under this assumption, wage levels would be too high for all types of labour experiencing an unemployment rate which is above the pre-specified 'frictional rate'. However, such an exercise is not undertaken here.

In my empirical analysis, I will choose a period of low unemployment as time $t$ and a period of high unemployment as time $t+\tau$. This guarantees that I observe a labour market moving into disequilibrium. It will be interesting to see how this movement into disequilibrium is related to the wage structure.

The parametric model presented in Section 3.2 identifies 'contributing factors' to 'wage rigidity dynamics'. These 'contributing factors' are characteristics which define heterogeneous types of labour. Take 'low level of education' as an example of such a factor. The econometric analysis proposed in Section 3.2 allows a statement on whether having a 'low level of education' ceteris paribus increases the chances of operating in a labour market with a 'wage rigidity dynamic'. In 
other words, my analysis identifies the factors to which wage rigidities are attached. The following two subsections present a model of the labour market and a possibility for its empirical application.

\subsection{Theory and Identification}

The framework I impose allows for the fact that labour is heterogeneous. One may think of the whole labour market of an economy as being composed of a set of specific labour markets defined by characteristics $\mathbf{x}$ (e.g. age, education, occupation-specific human capital, industry-specific human capital, region). Borrowing from the supply-demand-institutions framework outlined in Katz and Autor (1999), I set up the following model of the labour market with heterogeneous labour:

$$
\begin{array}{lr}
L_{t}=S_{t}\left(W_{t}, R_{t}\right) & \text { (vector of labour supplies) } \\
N_{t}=D_{t}\left(W_{t}, Z_{t}\right) & \text { (vector of labour demands) } \\
U_{\text {rigid wage rate, } t}=\left(L_{t}-N_{t}\right) / L_{t}=1-N_{t} / L_{t}=1-D_{t}\left(W_{t}, Z_{t}\right) / S_{t}\left(W_{t}, R_{t}\right)=\Psi_{t}\left(W_{t}, Q_{t}\right)
\end{array}
$$

(vector of unemployment rates)

$$
U_{\text {total }, t}=F_{t}\left(U_{\text {rigid wage rate }, t}, U_{\text {frictional }, t}\right)
$$

Here, $W_{t}$ and $U_{t}$ denote the vectors of wage and unemployment rates (numbers unemployed according to the International Labour Office (ILO) definition divided by the size of the labour force) at time $t$, respectively (each set of labour characteristics $\mathbf{x}$ has an element of $W_{t}$ and $U_{t}$ assigned). $S_{t}$ and $D_{t}$ are time-varying vector functions, and $R_{t}$ and $Z_{t}$ are vectors of 'shift factors' for the supply and demand functions, respectively. The shift factors in the labour supply function can be migration, changes in the educational structure, or tax changes. In the labour demand function, shift factors may be technology shocks or migration, for example. The notation $D_{t} / S_{t}$ denotes element-by-element division of the two vectors. The vector function $F_{t}$ relates the total (observed) unemployment rate to its two components, the unemployment rate due to rigid wages $U_{\text {rigid wage rate, } t}$ and the 'frictional unemployment rate' $U_{\text {frictional }, t}$, which is not modelled here. 
If in the above model there exists a vector of prices (wage rates) $W_{t}^{*}$ which clears the labour market, there will be no quantity rationing (unemployment $U_{\text {rigid wage rate, },}$ ) if wages are perfectly flexible. If unemployment $U_{\text {rigid wage rate, }}$ exists in spite of the existence of market clearing wages $W_{t}^{*}$, the reason must be 'rigid' wages. Hence this type of unemployment is termed 'unemployment due to rigid wages'. Trade union power is often discussed as a possible cause for wage rigidities, especially in Germany and other European countries (Carlin and Soskice, 1990, Chapter 17; Nickell, 1997; 1998; Siebert, 1997; Booth, 1995; Blau and Kahn, 1999; Fitzenberger and Franz, 1999; Franz, 1999; Kahn, 2000; Bonin and Zimmermann, 2001). However, other factors such as public sector pay scales or long-term wage contracts may also cause wages to be rigid.

The above model, unlike all studies mentioned in Section 2 except Kahn (2000), does allow for the existence of 'frictional unemployment'. This type of unemployment may exist in reality due to market frictions like incomplete information or transaction costs. Following the related literature, I do not model frictional unemployment explicitly, though. For the analysis which follows, the existence of frictional unemployment can be ignored under the following conditions, which I call assumption (b):

$$
\operatorname{sgn}\left(\Delta_{t}^{t+\tau} U(\mathbf{x})_{\text {total }}\right)=\operatorname{sgn}\left(\Delta_{t}^{t+\tau} U(\mathbf{x})_{\text {rigid wage rate }}\right) \quad \forall \mathbf{x}
$$

where $\mathbf{x}$ are the characteristics defining a labour market such that $U(\mathbf{x})_{\text {total, } t}$ is an element of the vector $U_{\text {total, },}$. Previous studies mentioned in Section 2 except Kahn (2000) do not discuss the potential implications of the existence of frictional unemployment. However, I argue that in order to make sense of their results on wages and (un-)employment, they must also assume that changes in frictional unemployment do not influence their statistical results. This is equivalent to implicitly imposing something similar to my assumption (b), which states that the sign of the change in the unemployment rate due to a rigid wage rate is the same as the sign of the change in the total (observed) unemployment rate. Hence, exogenous changes in the frictional unemployment are excluded. Of course, it would be preferable to measure frictional unemployment. However, currently existing data do not allow estimates of frictional unemployment (as defined here) at the disaggregated level. This is probably why this issue is usually being ignored in the literature. However, ignoring the topic is equivalent to making some implicit assumption. This is why I explicitly make the assumption necessary to ignore frictional unemployment. 
I now show that the two key assumptions (a: $D_{t+\tau, W}(\mathbf{x}, \mathbf{x}) \times S_{t+\tau}(\mathbf{x}, \mathbf{x})-$ $D_{t+\tau}(\mathbf{x}, \mathbf{x}) \times S_{t+\tau, W}(\mathbf{x}, \mathbf{x})<0 ; \quad$ explained below, and $\quad$ b: $\quad \operatorname{sgn}\left(\Delta_{t}^{t+\tau} U(\mathbf{x})_{\text {total }}\right)=$ $\left.\left.\operatorname{sgn}\left(\Delta_{t}^{t+\tau} U(\mathbf{x})_{\text {rigid wage rate }}\right) \forall \mathbf{x}\right)\right)$, are sufficient to identify wage rigidity dynamics. This implies that other methodologies, which make identifying assumptions on (the lack of) changes in labour supply or demand, put unnecessarily strong restrictions on their data ( $c f$. assumptions (i) and (ii) mentioned in Section 2).

Using a Taylor expansion of $U_{\text {rigid wage rate } t+\tau}$ around $\left(W_{t}, Q_{t}\right)$ and restricting changes in the functional form of $\Psi_{t}$ over time by the assumption $\Psi_{t}\left(W_{t}, Q_{t}\right)=\Psi_{t+\tau}\left(W_{t}, Q_{t}\right)$ (which still allows variations in the 'slopes' of the labour supply and demand schedules), the change in the unemployment rate vector due to rigid wages can be written as:

$$
\Delta_{t}^{t+\tau} U_{\text {rigid wage rate }} \approx \underbrace{\Psi_{t+\tau, W}\left(W_{t}, Q_{t}\right) \Delta_{t}^{t+\tau} W}_{\text {wage effects }}+\underbrace{\Psi_{t+\tau, Q}\left(W_{t}, Q_{t}\right) \Delta_{t}^{t+\tau} Q}_{\text {pure net supply shift effects }}
$$

where $\Psi_{t+\tau, W}\left(W_{t}, Q_{t}\right)$ and $\Psi_{t+\tau, Q}\left(W_{t}, Q_{t}\right)$ denote the Jacobian derivatives of $\Psi_{t+\tau}$ at $\left(W_{t}, Q_{t}\right)$ with respect to $W$ and $Q$, respectively. They shall henceforth be denoted $\Psi_{W}$ and $\Psi_{Q}$, respectively.

Assume one distinguishes between $N_{\mathbf{x}}$ different labour markets $\mathbf{x}$. Then, the vectors $\Delta_{t}^{t+\tau} U$ etc. have length $N_{\mathbf{x}}$. Considering the above equation for a specific row element $\mathbf{x}$ of vector $\Delta_{t}^{t+\tau} U$, one has: 


$$
\Delta_{t}^{t+\tau} U_{\text {rigid wage rate }}(\mathbf{x}) \approx \underbrace{\Psi_{W}(\mathbf{x}, \mathbf{x}) \Delta_{t}^{t+\tau} W(\mathbf{x})}_{\text {own wage effect }}+\underbrace{\underbrace{\sum_{\mathbf{X} \neq \mathbf{x}} \Psi_{W}(\mathbf{x}, \mathbf{X}) \Delta_{t}^{t+\tau} W(\mathbf{X})}_{\text {pross wage effects }}+\underbrace{\sum_{\mathbf{X}} \Psi_{Q}(\mathbf{x}, \mathbf{X}) \Delta_{t}^{t+\tau} Q(\mathbf{X})}_{\text {puply shift effects }}}_{\text {net supply shiff effects }}
$$

with

$$
\Psi_{W}(\mathbf{x}, \mathbf{x})>0
$$

due to assumption a) and

$$
\operatorname{sgn}\left(\Delta_{t}^{t+\tau} U(\mathbf{x})_{\text {total }}\right)=\operatorname{sgn}(\underbrace{\Psi_{W}(\mathbf{x}, \mathbf{x}) \Delta_{t}^{t+\tau} W(\mathbf{x})}_{\text {own wage effect }}+\underbrace{\sum_{\mathbf{X} \neq \mathbf{x}} \Psi_{W}(\mathbf{x}, \mathbf{X}) \Delta_{t}^{t+\tau} W(\mathbf{X})+\sum_{\mathbf{X}} \Psi_{Q}(\mathbf{x}, \mathbf{X}) \Delta_{t}^{t+\tau} Q(\mathbf{X})}_{\text {net supply shift effects }})
$$

because of assumption b).

$\Delta_{t}^{t+\tau} U(\mathbf{x}), \Delta_{t}^{t+\tau} W(\mathbf{x})$, and $\Delta_{t}^{t+\tau} Q(\mathbf{x})$ denote the elements of the respective vectors referring to labour market $\mathbf{x} . \Psi_{W}(\mathbf{x}, \mathbf{x})$ is the diagonal element of matrix $\Psi_{W}$ describing the own-wage unemployment effect in labour market $\mathbf{x} . \Psi_{W}(\mathbf{x}, \mathbf{X})$ is the off-diagonal element of matrix $\Psi_{W}$ describing the cross-wage unemployment effect on labour market $\mathbf{x}$ of a wage change in labour market $\mathbf{X} . \Psi_{Q}(\mathbf{x}, \mathbf{X})$ is defined analogously. In Appendix B., equation (1) is illustrated graphically. Appendix C. discusses this model in relation to the 'wage curve' hypothesis.

One can verify that $\quad \Psi_{W}(\mathbf{x}, \mathbf{x})>0$ if assumption (a): $D_{t+\tau, W}(\mathbf{x}, \mathbf{x}) \times S_{t+\tau}(\mathbf{x}, \mathbf{x})-D_{t+\tau}(\mathbf{x}, \mathbf{x}) \times S_{t+\tau, W}(\mathbf{x}, \mathbf{x})<0$ is met (due to the quotient rule for derivatives). As $D$ and $S$ are always positive functions, this assumption is fulfilled if $D_{t+\tau, W}(\mathbf{x}, \mathbf{x})<0$ ('downward sloping' demand curve) and $S_{t+\tau, W}(\mathbf{x}, \mathbf{x})>0$ ('upward sloping' supply curve). However, it is also met if $D_{t+\tau, W}(\mathbf{x}, \mathbf{x})<0$ and $S_{t+\tau, W}(\mathbf{x}, \mathbf{x})<0$ ('backward bending' labour supply) if $D_{t+\tau, W}(\mathbf{x}, \mathbf{x})<S_{t+\tau, W}(\mathbf{x}, \mathbf{x})$ (the labour demand is steeper than the labour supply curve) and $D_{t+\tau}(\mathbf{x}, \mathbf{x}) \leq S_{t+\tau}(\mathbf{x}, \mathbf{x})$ (there is no excess demand for labour). Other cases when 
assumption (a) is fulfilled can be thought of, but they are probably not so interesting from a labour economist's point of view.

From the perspective of agents in labour market $\mathbf{x}$, both the cross-wage effects and the 'pure' net supply shift effects appear as net supply (or net demand) shift effects (this is true irrespective of whether any two types of labour are gross substitutes or gross complements). For this reason, the terms $\sum_{\mathbf{X} \neq \mathbf{x}} \Psi_{W}(\mathbf{x}, \mathbf{X}) \Delta_{t}^{t+\tau} W(\mathbf{X})+\sum_{\mathbf{X}} \Psi_{Q}(\mathbf{x}, \mathbf{X}) \Delta_{t}^{t+\tau} Q(\mathbf{X})$ will henceforth together be called net supply shift effects (if one were to consider cross wage effects separately, further assumptions are required, as the matrix $\Psi_{W}$ contains $N_{\mathbf{X}}\left(N_{\mathbf{X}}-1\right)$ off-diagonal terms whose individual signs are unknown). A positive (negative) net supply shift effect means that at constant wages, supply increases (decreases) by more than demand. This can equivalently be called a negative (positive) net demand shift effect. A market which experiences a negative (positive) demand shift effect is called a 'decreasing' ('increasing') market in this paper (see also Appendix B.).

From equations (1) to (3) relating unemployment changes to wage and net supply shift effects, one may - by observing the signs of wage and unemployment changes in labour market $\mathbf{x}$ on the basis of assumptions (a) and (b) - draw the following conclusions on the net supply shift effects $\sum_{\mathbf{X} \neq \mathbf{x}} \Psi_{W}(\mathbf{x}, \mathbf{X}) \Delta_{t}^{t+\tau} W(\mathbf{X})+\sum_{\mathbf{X}} \Psi_{Q}(\mathbf{x}, \mathbf{X}) \Delta_{t}^{t+\tau} Q(\mathbf{X}):$

Table 2: Observed Signs of Wage and Unemployment Changes and Implications

\begin{tabular}{|c|c|c|c|}
\hline Case & $\begin{array}{l}\text { Observed sign of } \\
\qquad \Delta_{t}^{t+\tau} U(\mathbf{x})\end{array}$ & $\begin{array}{l}\text { Observed sign of } \\
\qquad \Delta_{t}^{t+\tau} W(\mathbf{x})\end{array}$ & $\begin{array}{c}\text { Implied sign of } \\
\sum_{\mathbf{X} \neq \mathbf{x}} \Psi_{W}(\mathbf{x}, \mathbf{X}) \Delta_{t}^{t+\tau} W(\mathbf{X})+ \\
\sum_{\mathbf{X}} \Psi_{Q}(\mathbf{x}, \mathbf{X}) \Delta_{t}^{t+\tau} Q(\mathbf{X})\end{array}$ \\
\hline (1) & + & + & $?$ \\
\hline (2) & - & - & $?$ \\
\hline (3) & + & - & + \\
\hline (4) & - & + & - \\
\hline (5) & + & 0 & + \\
\hline (6) & - & 0 & - \\
\hline (7) & 0 & + & - \\
\hline (8) & 0 & - & + \\
\hline (9) & 0 & 0 & 0 \\
\hline
\end{tabular}


Note that $\Delta_{t}^{t+\tau} U(\mathbf{x})$ shall henceforth denote $\Delta_{t}^{t+\tau} U(\mathbf{x})_{\text {total }}$. One knows from the model that a ceteris paribus increase (decrease) in the wage for a certain type of labour raises (lowers) unemployment for that type of labour. Thus if changes in the wage and in unemployment rates run in the same direction (cases (1) and (2) in Table 2), one can say that wage changes have in any case contributed to the changes in unemployment rates, although one cannot infer anything on the supply and demand shift factors. I call case (1) a 'strongly rigid' and case (2) a 'converging' wage behaviour. An alternative formulation for 'strongly rigid' and 'converging' may be 'wage push' and 'wage pull' behaviour, respectively. The 'strongly rigid' and 'converging' terminology for cases (1) and (2) is intuitive if the situation at time $t$ is one of no excess demand for labour. If wages and unemployment rates run in opposite directions (cases (3) and (4) in Table 2), one knows whether there has been a positive net supply or a positive net demand effect of changes in the 'shift' factors. Furthermore, wage developments do not fully neutralise net supply or net demand effects in these situations. Cases (3) and (4) are thus termed a 'weakly adjusting wage in a decreasing market' and a 'weakly adjusting wage in an increasing market', respectively.

If either wages or unemployment rates do not change (cases (5) to (8)), one can always infer the sign of the net supply effect of changes in the 'shift' factors. I call cases (5) and (6) 'weakly rigid wage behaviour in a decreasing' and 'increasing market', respectively. Wages here are 'rigid' in the sense that they do not counteract on the unemployment changes incurred by the net supply shift effects. Cases (7) and (8) are termed 'strongly adjusting wage behaviour in a decreasing' and 'increasing market', respectively. In these two situations, wage changes neutralise net supply or net demand effects. Therefore, this neutralising wage behaviour is termed 'strongly adjusting'. In case (9) nothing happens. I call this 'stable wages in a stable market'.

The following table defines a classification of wage behaviour and labour markets on the basis of empirical observations of wage and unemployment movements: 


\begin{tabular}{l|c|c|c}
\hline \hline & $\begin{array}{c}\text { Increasing wage } \\
\Delta_{t}^{t+\tau} W(\mathbf{x})>0\end{array}$ & $\begin{array}{c}\text { Constant wage } \\
\Delta_{t}^{t+\tau} W(\mathbf{x})=0\end{array}$ & $\begin{array}{c}\text { Decreasing wage } \\
\Delta_{t}^{t+\tau} W(\mathbf{x})<0\end{array}$ \\
\hline $\begin{array}{l}\text { Increasing unemployment } \\
\Delta_{t}^{t+\tau} U(\mathbf{x})>0\end{array}$ & $\begin{array}{c}\text { strongly rigid } \\
\text { (wage push) }\end{array}$ & $\begin{array}{c}\text { weakly rigid in } \\
\text { decreasing } \text { market }\end{array}$ & $\begin{array}{c}\text { weakly adjusting in } \\
\text { decreasing } \text { market }\end{array}$ \\
\hline $\begin{array}{l}\text { Constant unemployment } \\
\Delta_{t}^{t+\tau} U(\mathbf{x})=0\end{array}$ & $\begin{array}{c}\text { strongly adjusting in } \\
\text { increasing market }\end{array}$ & $\begin{array}{c}\text { stable in stable } \\
\text { market }\end{array}$ & $\begin{array}{c}\text { strongly adjusting in } \\
\text { decreasing market }\end{array}$ \\
\hline $\begin{array}{l}\text { Decreasing unemployment } \\
\Delta_{t}^{t+\tau} U(\mathbf{x})<0\end{array}$ & $\begin{array}{c}\text { weakly adjusting in } \\
\text { increasing market }\end{array}$ & $\begin{array}{c}\text { weakly rigid in } \\
\text { increasing market }\end{array}$ & $\begin{array}{c}\text { converging } \\
\text { (wage pull) }\end{array}$ \\
\hline \hline
\end{tabular}

The observation of an increase in the wage rate and the unemployment rate in a labour market between two points in time is, on the basis of my assumptions (a) and (b), defined as a 'strong wage rigidity dynamic'. The observation of a constant wage rate and an increase in the unemployment rate in a labour market between two points in time is defined as a 'weak wage rigidity dynamic in a decreasing market'. The two phenomena of a 'strong wage rigidity dynamic' and a 'weak wage rigidity dynamic in a decreasing market' are particularly interesting for the purposes this paper, as especially in these cases, 'rigid' wage behaviour as defined may be held responsible for rising unemployment rates. Note that in the case of a 'weak wage rigidity dynamic in an increasing market' wages are 'rigid' in the sense that they do not rise and thus they allow unemployment to fall. This case is not so interesting for my purposes, as I want to test whether wage increases are responsible for rising unemployment.

The recent literature has focussed much attention on the wage structure by comparing developments for different skill groups. The analysis of the wage structure is particularly interesting because it has been hypothesised that wages in Europe (including Germany) are rigid for low skilled workers (Krugman, 1994). This rigidity in the wage structure is claimed to have been the main culprit for rising unemployment in European countries like Germany. To test this hypothesis, one should inspect changes in the wage and unemployment structure separately from changes in average wage and unemployment rates.

Changes in the wage structure can be characterised by the difference between the wage and unemployment changes in labour market $\mathbf{x}$ and the changes in a (possibly hypothetical) reference market $\overline{\mathbf{x}}$ (which may represent some concept of 'average'): 


$$
\begin{aligned}
& \Delta_{t}^{t+\tau} W(\mathbf{x})-\Delta_{t}^{t+\tau} W(\overline{\mathbf{x}}) \\
& \Delta_{t}^{t+\tau} U(\mathbf{x})-\Delta_{t}^{t+\tau} U(\overline{\mathbf{x}})
\end{aligned}
$$

On the basis of the observation of these changes, I can observe and classify relative wageunemployment dynamics for the labour market $\mathbf{x}$ (in relation to the reference market $\overline{\mathbf{x}}$ ):

\begin{tabular}{|c|c|c|c|}
\hline & $\begin{array}{c}\text { Increasing relative } \\
\text { wage } \\
\Delta_{t}^{t+\tau} W(\mathbf{x})- \\
\Delta_{t}^{t+\tau} W(\overline{\mathbf{x}})>0\end{array}$ & $\begin{array}{l}\text { Constant relative } \\
\text { wage } \\
\begin{array}{l}\Delta_{t}^{t+\tau} W(\mathbf{x})- \\
\Delta_{t}^{t+\tau} W(\overline{\mathbf{x}})=0\end{array}\end{array}$ & $\begin{array}{c}\text { Decreasing relative } \\
\text { wage } \\
\begin{array}{c}\Delta_{t}^{t+\tau} W(\mathbf{x})- \\
\Delta_{t}^{t+\tau} W(\overline{\mathbf{x}})<0\end{array}\end{array}$ \\
\hline $\begin{array}{l}\text { Increasing relative } \\
\text { unemployment } \\
\Delta_{t}^{t+\tau} U(\mathbf{x})-\Delta_{t}^{t+\tau} U(\overline{\mathbf{x}})>0\end{array}$ & $\begin{array}{l}\text { strongly rigid } \\
\text { relative to the } \\
\text { reference market }\end{array}$ & $\begin{array}{l}\text { weakly rigid in a } \\
\text { decreasing market } \\
\text { relative to the } \\
\text { reference market }\end{array}$ & $\begin{array}{l}\text { weakly adjusting in } \\
\text { a decreasing market } \\
\text { relative to the } \\
\text { reference market }\end{array}$ \\
\hline $\begin{array}{l}\text { Constant relative } \\
\text { unemployment } \\
\Delta_{t}^{t+\tau} U(\mathbf{x})-\Delta_{t}^{t+\tau} U(\overline{\mathbf{x}})=0\end{array}$ & $\begin{array}{l}\text { strongly adjusting in } \\
\text { an increasing } \\
\text { market } \\
\text { relative to the } \\
\text { reference market }\end{array}$ & $\begin{array}{l}\text { stable in a stable } \\
\text { market } \\
\text { relative to the } \\
\text { reference market }\end{array}$ & $\begin{array}{l}\text { strongly adjusting in } \\
\text { a decreasing market } \\
\text { relative to the } \\
\text { reference market }\end{array}$ \\
\hline $\begin{array}{l}\text { Decreasing relative } \\
\text { unemployment } \\
\Delta_{t}^{t+\tau} U(\mathbf{x})-\Delta_{t}^{t+\tau} U(\overline{\mathbf{x}})<0\end{array}$ & $\begin{array}{l}\text { weakly adjusting in } \\
\text { an increasing } \\
\text { market } \\
\text { relative to the } \\
\text { reference market }\end{array}$ & $\begin{array}{l}\text { weakly rigid in an } \\
\text { increasing market } \\
\text { relative to the } \\
\text { reference market }\end{array}$ & $\begin{array}{l}\text { converging } \\
\text { relative to the } \\
\text { reference market }\end{array}$ \\
\hline
\end{tabular}

\section{Definition 2: Relative Wage Behaviour and Labour Market Classification}

Hence, the observation of a relative (to the reference market) increase in the wage rate and the unemployment rate in a labour market between two points in time is defined as a 'strong relative wage rigidity dynamic'. The observation of a constant relative wage rate and a relative (to the reference market) increase in the unemployment rate in a labour market between two points in time is defined as a 'weak relative wage rigidity dynamic in a decreasing market'. The two phenomena of a 'strong relative wage rigidity dynamic' and a 'weak relative wage rigidity dynamic in a decreasing market' are particularly interesting for the purposes of the empirical part of the paper.

Note that Definition 2 just 'shifts the scale' of Definition 1 by subtracting averages from the wage and unemployment changes. Definition 1 refers to absolute wage and unemployment changes, whereas Definition 2 refers to the wage and unemployment changes in relation to the reference 
market $\overline{\mathbf{x}}$. Hence, a labour market $\mathbf{x}$ may be classified as strongly rigid in an absolute sense, but converging in a relative sense if wage and unemployment increases in this market are below the wage and unemployment increases in the reference market $\overline{\mathbf{x}}$.

The following section proposes how relative wage-unemployment dynamics may be estimated empirically with unbalanced panel data (the type of data I use for western Germany).

\subsection{Estimation with Unbalanced Panel Data}

Realistically, each labour market $\mathbf{x}$ will still show some dispersion in wages and unemployment likelihoods across workers (i.e. some heterogeneity between workers will be unobserved). Therefore, it makes sense to talk of expected values of wage rates and unemployment likelihoods over individuals within market $\mathbf{x}$. Hence I define:

$$
\begin{aligned}
& W_{t}(\mathbf{x}) \equiv E\left(w_{t} \mid \mathbf{x}\right) \\
& U_{t}(\mathbf{x}) \equiv E\left(u_{t} \mid \mathbf{x}\right)
\end{aligned}
$$

where $w_{t}$ is the hourly wage rate and $u_{t}$ is a binary variable indicating whether a person is unemployed at time $t$. Wage and unemployment dynamics between points in time $t$ and $t+\tau$ for labour market $\mathbf{x}$ are defined as:

$$
\begin{gathered}
\Delta_{t}^{t+\tau} W(\mathbf{x})=E\left(w_{t+\tau} \mid \mathbf{x}\right)-E\left(w_{t} \mid \mathbf{x}\right)=E\left(w_{t+\tau}-w_{t} \mid \mathbf{x}\right) \\
\Delta_{t}^{t+\tau} U(\mathbf{x})=E\left(u_{t+\tau} \mid \mathbf{x}\right)-E\left(u_{t} \mid \mathbf{x}\right)=E\left(u_{t+\tau}-u_{t} \mid \mathbf{x}\right)
\end{gathered}
$$

Relative wage and unemployment dynamics between points in time $t$ and $t+\tau$ for labour market $\mathbf{x}$ are defined as:

$$
\begin{gathered}
\Delta_{t}^{t+\tau} W(\mathbf{x})-\Delta_{t}^{t+\tau} W(\overline{\mathbf{x}})=E\left(w_{t+\tau}-w_{t} \mid \mathbf{x}\right)-E\left(w_{t+\tau}-w_{t} \mid \overline{\mathbf{x}}\right) \\
\Delta_{t}^{t+\tau} U(\mathbf{x})-\Delta_{t}^{t+\tau} U(\overline{\mathbf{x}})=E\left(u_{t+\tau}-u_{t} \mid \mathbf{x}\right)-E\left(u_{t+\tau}-u_{t} \mid \overline{\mathbf{x}}\right)
\end{gathered}
$$

The high number of cells defined by all possible realisations of $\mathbf{x}$ and the potentially low number of observations in these cells make it difficult to estimate $E\left(w_{t+\tau}-w_{t} \mid \mathbf{x}\right)$ and $E\left(u_{t+\tau}-u_{t} \mid \mathbf{x}\right)$ for all 
realisations of $\mathbf{x}$. This dimensionality problem can be reduced by parameterising the conditional distribution of wages and unemployment. Frequently applied models are:

$$
\begin{gathered}
E\left(\ln w_{t} \mid \mathbf{x}\right)=\boldsymbol{\beta}_{t}^{\prime} \mathbf{x} \Leftrightarrow E\left(w_{t} \mid \mathbf{x}\right)=\exp \left\{\boldsymbol{\beta}_{t}^{\prime} \mathbf{x}+0.5 \times \sigma_{t}^{2}\right\} \\
E\left(u_{t} \mid \mathbf{x}\right)=\Phi\left(\gamma_{t}^{\prime} \mathbf{x}\right)
\end{gathered}
$$

where $\sigma_{t}^{2}=\operatorname{Var}\left(\ln w_{t} \mid \mathbf{x}\right)$ and $\Phi(\cdot)$ denotes the cumulative distribution function of the standard normal distribution. Hence, I specify a log-linear model for the conditional wage and a probit model for the conditional unemployment expectations, respectively (see e.g. Mittelhammer, Judge, and Miller, 2000, Chapter E1, for the expected value of the log-normal distribution). These models are estimated for the time periods $t$ and $t+\tau$. Note that this parameterisation implies that the effect of any characteristic $x_{k}$ on the wage and unemployment dynamic is driven by the same coefficient changes $\left(\beta_{t+\tau, k}-\beta_{t, k}\right)$ and $\left(\gamma_{t+\tau, k}-\gamma_{t, k}\right)$ in all labour markets. This type of restriction is in the nature of parametric models.

In Appendix A., it is demonstrated that instead of describing the relative wage and unemployment dynamics for all possible labour markets $\mathbf{x}$, one can just report the $K$ dynamics related to the defining characteristics $x_{k}$ (where $K$ is the length of vector $\mathbf{x}, x_{k}$ is an element of $\mathbf{x}$; in my case, $\mathbf{x}$ contains only dummy variables). It is shown that there exists a transformation $\beta_{t, k}^{*}, \beta_{t+\tau, k}^{*}, \gamma_{t, k}^{*}, \gamma_{t+\tau, k}^{*}$ of the regression coefficient vectors $\beta_{t, k}, \beta_{t+\tau, k}, \gamma_{t, k}, \gamma_{t+\tau, k}$ for which it is true that the signs of the coefficient differences $\left(\beta_{t+\tau, k}^{*}-\beta_{t, k}^{*}\right)$ and $\left(\gamma_{t+\tau, k}^{*}-\gamma_{t, k}^{*}\right)$ for characteristic $x_{k}$ equal the signs of the contributions of this characteristic to the relative wage and unemployment dynamics $\left[E\left(w_{t+\tau}-w_{t} \mid \mathbf{x}\right)-E\left(w_{t+\tau}-w_{t} \mid \overline{\mathbf{x}}\right)\right]$ and $\left[E\left(u_{t+\tau}-u_{t} \mid \mathbf{x}\right)-E\left(u_{t+\tau}-u_{t} \mid \overline{\mathbf{x}}\right)\right]$, respectively. In other words, if $\left(\beta_{t+\tau, k}^{*}-\beta_{t, k}^{*}\right)$ is positive, then being in a labour market which has characteristic $x_{k}$ raises the expected relative wage change $\left[E\left(w_{t+\tau}-w_{t} \mid \mathbf{x}\right)-E\left(w_{t+\tau}-w_{t} \mid \overline{\mathbf{x}}\right)\right]$. Note that due to the non-linear model specifications, this result is not at all obvious. For example, the statement does not generally hold for the sign of the differences in the untransformed coefficients $\left(\beta_{t+\tau, k}-\beta_{t, k}\right)$ and $\left(\gamma_{t+\tau, k}-\gamma_{t, k}\right)$ because of the non-linear nature of the models. The derivation is found in Appendix A. 
The contribution to relative wage and unemployment behaviour can thus be defined for a labour market characteristic $x_{k}$ on the basis of the signs of the coefficient changes $\left(\beta_{t+\tau, k}^{*}-\beta_{t, k}^{*}\right)$ and $\left(\gamma_{t+\tau, k}^{*}-\gamma_{t, k}^{*}\right):$

Definition 3: Classification of Contribution of a Labour Market Characteristic $x_{k}$ to Relative Wage Behaviour

\begin{tabular}{l|c|c|c}
\hline \hline & $\begin{array}{c}\text { Contributing to a } \\
\text { relative wage } \\
\text { increase } \\
\left(\beta_{t+\tau, k}^{*}-\beta_{t, k}^{*}\right)>0\end{array}$ & $\begin{array}{c}\text { Contributing to a } \\
\text { constant relative } \\
\text { wage } \\
\left(\beta_{t+\tau, k}^{*}-\beta_{t, k}^{*}\right)=0\end{array}$ & $\begin{array}{c}\text { Contributing to a } \\
\text { relative wage } \\
\text { decrease } \\
\left(\beta_{t+\tau, k}^{*}-\beta_{t, k}^{*}\right)<0\end{array}$ \\
\hline $\begin{array}{l}\text { Contributing to a } \\
\text { relative unemployment } \\
\text { increase }\end{array}$ & $\begin{array}{c}\text { contributing to a } \\
\text { strong relative wage } \\
\text { rigidity dynamic }\end{array}$ & $\begin{array}{c}\text { contributing to a } \\
\text { weak relative wage } \\
\text { rigidity dynamic in a } \\
\left.\gamma_{t+\tau, k}^{*}-\gamma_{t, k}^{*}\right)>0\end{array}$ & $\begin{array}{c}\text { contributing to a } \\
\text { weak relative wage } \\
\text { adjustment dynamic } \\
\text { in a decreasing } \\
\text { market }\end{array}$ \\
\hline $\begin{array}{l}\text { Contributing to a } \\
\text { constant relative } \\
\text { unemployment } \\
\left(\gamma_{t+\tau, k}^{*}-\gamma_{t, k}^{*}\right)=0\end{array}$ & $\begin{array}{c}\text { contributing to a } \\
\text { strong relative wage } \\
\text { adjustment dynamic } \\
\text { in an increasing } \\
\text { market }\end{array}$ & $\begin{array}{c}\text { contributing to a } \\
\text { relatively stable } \\
\text { market }\end{array}$ & $\begin{array}{c}\text { contributing to a } \\
\text { strong relative wage } \\
\text { adjustment dynamic } \\
\text { in a decreasing } \\
\text { market }\end{array}$ \\
\hline $\begin{array}{l}\text { Contributing to a } \\
\text { relative unemployment } \\
\text { decrease } \\
\left(\gamma_{t+\tau, k}^{*}-\gamma_{t, k}^{*}\right)<0\end{array}$ & $\begin{array}{c}\text { contributing to a } \\
\text { weak relative wage } \\
\text { adjustment dynamic } \\
\text { in an increasing } \\
\text { market }\end{array}$ & $\begin{array}{c}\text { contributing to a } \\
\text { weak relative wage } \\
\text { rigidity dynamic in } \\
\text { an increasing } \\
\text { market }\end{array}$ & $\begin{array}{c}\text { contributing to a } \\
\text { relative wage } \\
\text { convergence } \\
\text { dynamic }\end{array}$ \\
\hline \hline
\end{tabular}

In analogy to the definitions above, the two phenomena of a 'contribution to a strong relative wage rigidity dynamic' and a 'contribution to a weak relative wage rigidity dynamic in a decreasing market' are particularly interesting for the purposes of the empirical part of the paper.

If two independently-drawn cross sections of data were available for the same population, one could estimate the coefficient vectors $\beta_{t, k}^{*}, \beta_{t+\tau, k}^{*}, \gamma_{t, k}^{*}$ and $\gamma_{t+\tau, k}^{*}$ in four separate regressions (wage regressions for $\beta_{t, k}^{*}, \beta_{t+\tau, k}^{*}$ and probit regressions for $\gamma_{t, k}^{*}, \gamma_{t+\tau, k}^{*}$ ). It may be justifiable to assume that the four estimates are independent in this case. However, with unbalanced panel data with random entry and attrition (assumptions which I make), one may obtain efficiency gains by estimating joint wage as well as joint unemployment regressions for the two points in time $t$ and $t+\tau$. Thus I estimate an unbalanced panel equivalent to a seemingly unrelated regressions (SUR) 
model for the wage regressions. For the unemployment regressions, I estimate the probit equivalent to a SUR model for unbalanced panel data. As Monte-Carlo evidence suggests that the attempt to correct for sample selection in wage regressions may be futile if adequate instruments are not available, I do not correct for sample selection (see e.g. Leung and Yu, 1996, for a Monte Carlo study or Puhani, 2000a, for a survey of such Monte-Carlo studies). In the following, I present the econometric models which are implemented in this study:

The model for the (reduced-form) wage regressions is

$$
\begin{array}{ll}
\ln w_{t, i}=\mathbf{x}_{t, i} \boldsymbol{\beta}_{t}+\varepsilon_{t, i} & E\left[\varepsilon_{t, i} \mid \mathbf{x}_{t, i}\right]=0 \\
\ln w_{t+\tau, i}=\mathbf{x}_{t+\tau, i} \boldsymbol{\beta}_{t+\tau}+\varepsilon_{t+\tau, i} & \text { with } \\
& E\left[\varepsilon_{t+\tau, i} \mid \mathbf{x}_{t+\tau, i}\right]=0
\end{array}
$$

Observations $i$ are assumed to be independent drawings. Furthermore, I assume random entry and attrition with indicator $R_{W}$ which takes on realisation $r_{w, t, i}=1$ if person $i$ is in the wage regression sample at time $t$ (and 0 otherwise). The likelihood function to be maximised is:

$$
\begin{gathered}
\ell\left(\boldsymbol{\beta}_{t}, \boldsymbol{\beta}_{t+\tau}, \sigma_{t}^{2}, \sigma_{t+\tau}^{2}, \rho_{W} \mid \mathbf{W}_{N}, \mathbf{X}_{N}, \mathbf{R}_{W, N}\right)= \\
\prod_{i=1}^{N} \phi_{(2)}\left(\frac{\ln w_{t, i}-\mathbf{x}_{t, i} \boldsymbol{\beta}_{t}}{\sigma_{t}^{2}}, \frac{\ln w_{t+\tau, i}-\mathbf{x}_{t+\tau, i} \boldsymbol{\beta}_{t+\tau}}{\sigma_{t+\tau}^{2}}, \rho_{W}\right)^{r_{w, t, i} r_{w, t+\tau, i}} \\
\times \phi_{(1)}\left(\frac{\ln w_{t, i}-\mathbf{x}_{t, i} \boldsymbol{\beta}_{t}}{\sigma_{t}^{2}}\right)^{r_{w, t, i}\left(1-r_{w, t+\tau, i}\right)} \times \phi_{(1)}\left(\frac{\ln w_{t+\tau, i}-\mathbf{x}_{t+\tau, i} \boldsymbol{\beta}_{t+\tau}}{\sigma_{t+\tau}^{2}}\right)^{\left(1-r_{w, t, i}\right) r_{w, t+\tau, i}}
\end{gathered}
$$

with $\rho_{W}=\left[\sigma_{t, t+\tau} /\left(\sigma_{t} \sigma_{t+\tau}\right)\right] . \phi_{(1)}(\cdot)$ and $\phi_{(2)}(\cdot)$ denote the standard normal and standardised bivariate normal density functions, respectively (see also Greene, 2000, p. 849; Poirier, 1995, p. 121). $N$ is the number of observed individuals. Maximising this likelihood function will yield consistent and efficient estimates if the error terms have a multivariate normal distribution:

$$
\left(\varepsilon_{t, i}, \varepsilon_{t+\tau, i}\right) \sim N\left(0, \Sigma_{W}\right) ; \quad \Sigma_{W}=E\left[\left(\varepsilon_{t, i}, \varepsilon_{t+\tau, i}\right)\left(\varepsilon_{t, i}, \varepsilon_{t+\tau, i}\right)^{\prime}\right]=\left[\begin{array}{cc}
\sigma_{t}^{2} & \sigma_{t, t+\tau} \\
\sigma_{t, t+\tau} & \sigma_{t+\tau}^{2}
\end{array}\right] \forall i
$$

However, maximum likelihood estimation are still consistent (but not efficient) if this is not the case, as long as the distribution of the error terms belongs to the quadratic exponential family 
(Gourieroux, Monfort, and Trognon, 1984). However, maximum likelihood estimates of standard errors based on the inverse Hessian are inconsistent. Therefore, I estimate robust standard errors.

The model for the (reduced-form) unemployment regressions is:

$$
\begin{aligned}
& \tilde{u}_{t, i}=\mathbf{x}_{t, i} \gamma_{t}+\eta_{t, i} ; \quad u_{t, i}=1\left(\tilde{u}_{t, i}>0\right) \\
& \tilde{u}_{t+\tau, i}=\mathbf{x}_{t+\tau, i} \gamma_{t+\tau}+\eta_{t+\tau, i} ; \quad u_{t+\tau, i}=1\left(\tilde{u}_{t+\tau, i}>0\right) \\
& \text { with } E\left[\eta_{t, i} \mid \mathbf{x}_{t, i}\right]=0 \\
& E\left[\eta_{t+\tau, i} \mid \mathbf{x}_{t+\tau, i}\right]=0 \text { and } \\
& \left(\eta_{t, i}, \eta_{t+\tau, i}\right) \sim N\left(0, \Sigma_{U}\right) ; \quad \Sigma_{U}=E\left[\left(\eta_{t, i}, \eta_{t+\tau, i}\right)\left(\eta_{t, i}, \eta_{t+\tau, i}\right)^{\prime}\right]=\left[\begin{array}{cc}
1 & \rho_{U} \\
\rho_{U} & 1
\end{array}\right] \quad \forall i
\end{aligned}
$$

Here I make the assumption of joint normality of the errors, as no pseudo maximum likelihood estimator exists, to my knowledge, in case it is violated. Under the assumptions of independent drawings and random entry and attrition, the likelihood function is

$$
\begin{gathered}
\ell\left(\boldsymbol{\gamma}_{t}, \boldsymbol{\gamma}_{t+\tau}, \rho_{U} \mid \mathbf{U}_{N}, \mathbf{X}_{N}, \mathbf{R}_{U, N}\right)= \\
\prod_{i=1}^{N} \Phi_{(2)}\left[\left(2 u_{t . i}-1\right) \mathbf{x}_{t . i} \gamma_{t},\left(2 u_{t+\tau . i}-1\right) \mathbf{x}_{t+\tau, i} \gamma_{t+\tau},\left(2 u_{t . i}-1\right)\left(2 u_{t+\tau, i}-1\right) \rho_{U}\right]^{r_{u, t, i} r_{u, t+\tau, i}} \times \\
\Phi_{(1)}\left[\left(2 u_{t . i}-1\right) \mathbf{x}_{t . i} \gamma_{t}\right]^{r_{u, t . i}\left(1-r_{u, t+\tau, i}\right)} \times \Phi_{(1)}\left[\left(2 u_{t+\tau, i}-1\right) \mathbf{x}_{t+\tau, i} \gamma_{t+\tau}\right]^{\left(1-r_{u, t . i}\right) r_{u, t+\tau, i}}
\end{gathered}
$$

$\Phi_{(1)}(\cdot)$ and $\Phi_{(2)}(\cdot)$ denote the standard normal and standardised bivariate normal cumulative density functions, respectively (see also Greene, 2000, p. 849; Poirier, 1995, p. 121). Note that $u$ is the binary dependent variable (unemployed) here, not an error term. I maximise the just presented likelihood functions using the econometric software stata 6.0.

In the following section, the methodology I propose is applied to west German data from 1992 and 1998.

\section{Empirical Application: Western Germany}

\subsection{Data}

In order to test whether rising unemployment has been mainly related to rigidities in the west German wage structure, one would like to observe micro-level data on wages and unemployment for a period of rising average unemployment. (Note that this is not sampling on the endogenous 
outcome, as the endogenous outcome is the joint behaviour of unemployment and wages). For western Germany in the 1990s, the comparison of the years 1992 (where unemployment has been low) and 1997/1998 (up to where unemployment rose) seems appropriate for the current purpose. The analysis of wage and unemployment structures proposed in this paper requires representative individual data files for western Germany with information both on wages and unemployment. The German Socio-Economic Panel (GSOEP), the Microcensus (Mikrozensus), and the IABS are potential candidates. Although the Microcensus has a high number of observations as an important advantage over the GSOEP, it has unfortunately not been carried out in 1992. It is also not possible to work with this data set outside Germany. Furthermore, the wage information is only given in intervals. The IABS data file is also attractive due to its large sample size, but unemployment is measured as registered unemployment (whereas unemployment according to the ILO definition, see below, seems more appropriate). Moreover, wages are censored above the social security threshold level in the IABS. For these reasons, I choose to carry out the analysis with GSOEP data (detail on the GSOEP can be obtained from the internet page: http://www.diwberlin.de/english/sop/index.html).

For reasons mentioned in the above paragraph, the 1992 and 1998 waves are picked for the econometric analysis. The sample selection criteria are described in Table A1 in Appendix D. Unemployment rates (both average and by socio-economic characteristic) are reported for the years 1992, 1994, 1996, and 1998 for the (unweighted) samples in Table A2 in Appendix D. As explained in a footnote to the table, GSOEP data suggest that the peak in west German unemployment was in 1998 and not in 1997 (as official data suggest). Hence my choice of 1998 as the end of the investigated period.

In the sample, only people aged between 16 and 65 are included. The labour market defining characteristics $\mathbf{x}$ used for estimation are reported together with their sample means in Table A3 of Appendix D. I use the variables age, education, gender, occupation, industry, sector of employment (public/private), and Bundesland (region) and code them as dummy variable groups. Variables carrying a 'skill' dimension which may be ordered are age, education, and occupation. Thus, I distinguish between different dimensions of skill. The dependent variable in the wage regressions is the natural logarithm of the real hourly wage rate (measured in 1998 Deutsche Marks). In the unemployment equations, the dependent variable is equal to 1 if a person is unemployed and $O$ if employed (non-participants in the labour market are irrelevant in this study). Unemployment is defined very similar to the standard of the International Labour Office (ILO). 
The ILO criteria for being unemployed are that somebody is not working in the reference week, is looking for a job, and is ready to take up a job in the very short term. The GSOEP has information on whether a person is working and whether he or she is ready to take up an offered job very soon. The difference to the ILO criteria is that the GSOEP asks whether somebody 'definitely plans to work in the future', but not whether somebody is 'now looking for work'. However, the definition of unemployment used here is still very close to the one used by the ILO. The variables industry, occupation, and sector of employment (public/private) are proxies for human capital which somebody supplies to the labour market. As the 'current' values of these variables are potentially endogenous to both the wage and the unemployment equations (as set up in Section 3.2 above), I use the characteristics stated in the most recent of the previous three GSOEP waves (i.e. the previous three years) as a proxy for industry etc. specific human capital. As the number of unemployed people in the samples is 228 and 350 in the 1992 and 1998 waves, respectively, a rough coding of industry and occupation categories is necessary to allow precise estimates. For the same reason, I do not split the sample according to gender. As too few unemployed managers and farmers are in the sample, I exclude these groups from the estimation. As the GSOEP is made up of certain subsamples whose relative weights are changing over time, I control for these changing weights by including dummy variables indicating the subsample. These dummy variables are only included for this purpose and are not interpreted as labour market defining characteristics (their coefficients are available from the author upon request). Empirical results are presented in the following subsection.

\subsection{Empirical Results}

The estimated vectors $\left(\hat{\boldsymbol{\beta}}_{t+\tau}^{*}-\hat{\boldsymbol{\beta}}_{t}^{*}\right)$ and $\left(\hat{\boldsymbol{\gamma}}_{t+\tau}^{*}-\hat{\boldsymbol{\gamma}}_{t}^{*}\right)$ are reported together with appropriate $t$-statistics in Table 3. Inference is based on separate $t$-tests on the coefficient changes $\left(\hat{\boldsymbol{\beta}}_{t+\tau}^{*}-\hat{\boldsymbol{\beta}}_{t}^{*}\right)$ and $\left(\hat{\gamma}_{t+\tau}^{*}-\hat{\gamma}_{t}^{*}\right)$. Sizes of 5 per cent of these $t$-tests correspond to a level of 10 per cent (which is the upper bound of the true size, the lower bound being 5 per cent) of the Bonferroni joint test of the null hypothesis $\left(\hat{\beta}_{t+\tau, k}^{*}-\hat{\beta}_{t, k}^{*}\right)=\left(\hat{\gamma}_{t+\tau, k}^{*}-\hat{\gamma}_{t, k}^{*}\right)=0$ (see e.g. Mittelhammer, Judge, and Miller, 2000, p. 73 f.). As I do not want the level of the joint test to exceed 10 per cent, I only consider 5 per cent critical values for the $t$-statistics.

The transferred coefficients on the constant referring to the 1992 sample mean $\overline{\mathbf{x}}_{t}$ (which is chosen as the reference $\overline{\mathbf{x}}$ for both periods $t$ and $t+\tau$ ) show that 'on average', the likelihood of being 
unemployed increased significantly between 1992 and 1998. Also real wages increased significantly on average. Hence, there has been a 'strong wage rigidity dynamic' (as defined in Section 3) between 1992 and 1998 attached to the wage of the 'average' (1992) worker in western Germany.

The main focus of this study, however, is on the wage structure, i.e. on relative wage and unemployment changes. It is of particular interest whether potentially rising relative unemployment of low-skilled workers can be traced back to a rise in the relative wage of this group. To this end, the coefficient changes $\left(\hat{\boldsymbol{\beta}}_{t+\tau}^{*}-\hat{\boldsymbol{\beta}}_{t}^{*}\right)$ and $\left(\hat{\boldsymbol{\gamma}}_{t+\tau}^{*}-\hat{\boldsymbol{\gamma}}_{t}^{*}\right)$ have to be observed for the labour market defining characteristics $\mathbf{x}$ (see also the methodological discussion in Section 3 and Appendix A.).

Table 3 reveals that western Germany has seen few changes in both the wage and unemployment structures between 1992 and 1998. (The reader interested in the estimated wage and unemployment differentials in the years 1992 and 1998 is referred to Tables A4 and A5 in Appendix D., respectively). The only significant changes at the 5 per cent level in the wage structure are observed for the categories professional occupation, a group which could increase its positive wage differential further with respect to the mean, and higher education (between 15 and 20 years of education), for which there was a fall in the wage premium. At the 10 per cent significance level, one observes a decrease in the relative wage position of white-collar workers. The result that the west German wage structure has been relatively stagnant is not that surprising. Previous papers have reached similar conclusions for the 1980s and early 1990s (Abraham and Houseman, 1995; Freeman and Katz, 1995; Nickell and Bell, 1996; OECD, 1996; Krueger and Pischke, 1997; Steiner and Wagner, 1998; Freeman and Schettkat, 1999; 2000; Katz and Autor, 1999). There is also other evidence based on GSOEP data on the stable or declining highereducation wage premium over the late 1980s and early to mid 1990s (Boockmann and Steiner, 2000; Lauer and Steiner, 2000). Other studies on western Germany using a large data set on individual earnings $(I A B S)$ find that there have been some changes in the wage structure in the 1980s and early 1990s, but the view that there have only been small alterations compared to the developments in the United States is not challenged (Fitzenberger and Franz, 1998; Fitzenberger 1999; Möller, 1999). In the United States, by contrast, educational and skill premia have risen substantially during that period (Bound and Johnson, 1992; Katz and Murphy, 1992; Juhn, Murphy, and Pierce, 1993; Katz and Autor, 1999). 
Having established that the west German wage structure has been fairly stagnant between 1992 and 1998, the question arises whether this has had implications on the unemployment structure. It is a contribution of this paper to systematically compare ceteris paribus changes in the wage structure with changes in the unemployment structure on the basis of the methodology developed in Section 3. As Table 3 shows, there were few, but some, changes in the unemployment structure. Groups whose relative unemployment likelihood increased during the observation period are young people aged between 16 and 25, white-collar workers, and males (the change for the latter is only significant at the 10 per cent level). Groups whose relative unemployment likelihood decreased are workers aged between 46 and 55, females, and workers with no previous employment in the occupation dummy variable group (all significant only at the 10 per cent level).

Applying Definition 3 (see Section 3.2), the labour market characteristics $\mathbf{x}$ (which are the regressors of the wage and unemployment models) can be classified according to their contribution to relative wage behaviour. This classification is shown in Table 4 (for reasons stated below the table, only coefficient changes individually significant at the 5 per cent level are inferred as being unequal to zero). The west German wage structure exhibited no characteristic 'contributing to a strong relative wage rigidity dynamic'. However, being young (aged 16 to 25 years) or a whitecollar worker 'contributed to a weak relative wage rigidity dynamic in a decreasing market': the relative unemployment likelihood for these groups fell and relative wages remained stable (ceteris paribus). One may thus conclude that for these groups, a lack in the downward flexibility of the wage rate contributed to rising unemployment. The characteristics young age and white-collar occupation are attached to 12 and 41 per cent of the 1998 labour force sample, respectively (see Table A3 in Appendix D.). This finding thus carries some significance for the judgement of the rigidity of the west German wage structure as a whole. As to the rising youth unemployment problem in Germany, it is also documented in Zimmermann (2000). Although wages for young workers are already relatively low, labour plus other costs incurred by employers in the German vocational education system may still be too high to 'clear' the labour market. Young workers seem to have paid a price in terms of higher unemployment for the fact that the west German wage structure did not allow returns to age (experience) to increase. It is well documented that returns to experience increased in the United States in the 1980s and early 1990s (Katz and Murphy, 1992; Murphy and Welch, 1992; Juhn, Murphy, and Pierce, 1993; Freeman and Katz, 1995; Katz and Autor, 1999). A slight surprise may be the finding that the characteristic white-collar worker 'contributed to a weak relative wage rigidity dynamic' in the observation period. It was this group, 
not blue-collar workers, which was hit by a negative relative net demand shock during the observation period.

It is interesting to observe that a falling higher education (between 15 and 20 years of education) wage premium is not associated with any changes in the educational unemployment structure. This partly supports evidence from Krueger and Pischke (1997) that the stagnant wage structure did not cause unemployment in western Germany. The result for professional workers ('increasing market') is probably not surprising.

To sum up, apart from an increase in both the average wage and unemployment rate between 1992 and 1998, I find some evidence for rigidities in the west German wage structure. These rigidities are related to the returns on young age and white-collar occupation. However, they are not related to the returns to education. In particular, there have been no changes in the unemployment likelihoods between different educational groups and there has also been no relative increase in the unemployment incidence of blue-collar workers. Instead, white-collar workers were increasingly hit by unemployment in western Germany in the 1990s. These findings qualify Krugman's hypothesis that rising unemployment in Europe (especially for the low-skilled) and increasing wage dispersion in the United states are 'two sides of the same coin' (Krugman, 1994, p. 37), namely a fall in the relative demand for low-skilled labour. Whereas the differences in the wage experiences between the United States and western Germany are well documented empirically, I have shown that western Germany has - contrary to what might have been presumed - not seen an increase in relative unemployment of less educated workers once one controls for other individual characteristics relevant for labour market outcomes. My econometric (ceteris paribus) results thus substantiate Nickell and Bell's $(1995 ; 1996)$ argument that the relative unemployment rates of the less educated did not rise in western Germany in the 1980s and early 1990s. An explanation for this finding may be found in empirical evidence on test scores of German and U.S. American citizens. It reveals that the 'low-skilled' German labour force is significantly better educated than the 'low-skilled' American one: this could be the reason why relative earnings of 'low-skilled' German workers did not have to fall in order to prevent relative unemployment rises for this group (Nickell and Bell, 1996; Freeman and Schettkat 1999; 2000). 


\begin{tabular}{|c|c|c|c|c|}
\hline & \multicolumn{2}{|c|}{ Wage Regressions } & \multicolumn{2}{|c|}{ Unemployment Regressions } \\
\hline & $\left(\hat{\boldsymbol{\beta}}_{t+\tau}^{*}-\hat{\boldsymbol{\beta}}_{t}^{*}\right)$ & $t$-value & $\left(\hat{\gamma}_{t+\tau}^{*}-\hat{\gamma}_{t}^{*}\right)$ & $t$-value \\
\hline 1992 Sample Mean & $0.041 * *$ & 3.35 & $0.344 * *$ & 5.09 \\
\hline \multicolumn{5}{|l|}{ Age in years } \\
\hline $16-25$ & 0.027 & 0.70 & $0.327 * *$ & 3.25 \\
\hline $26-35$ & -0.008 & -0.46 & -0.093 & -1.27 \\
\hline $36-45$ & 0.015 & 1.02 & 0.055 & 0.66 \\
\hline $46-55$ & -0.021 & -1.25 & $-0.165^{*}$ & -1.72 \\
\hline $56-65$ & -0.023 & -0.72 & -0.113 & -0.66 \\
\hline \multicolumn{5}{|l|}{ Education in years } \\
\hline $0-8$ & -0.021 & -0.68 & -0.046 & -0.33 \\
\hline 9 & -0.008 & -0.29 & 0.105 & 0.89 \\
\hline $10-11$ & 0.005 & 0.62 & 0.003 & 0.06 \\
\hline $12-13$ & 0.030 & 1.35 & -0.142 & -1.19 \\
\hline 14 & 0.042 & 1.16 & -0.036 & -0.14 \\
\hline $15-20$ & $-0.052 * *$ & -1.96 & 0.078 & 0.44 \\
\hline \multicolumn{5}{|l|}{ Gender } \\
\hline male & 0.003 & 0.43 & $0.079 *$ & 1.85 \\
\hline female & -0.005 & -0.43 & $-0.111^{*}$ & -1.85 \\
\hline \multicolumn{5}{|l|}{ Occupation } \\
\hline professional & $0.053 * *$ & 2.29 & -0.204 & -1.22 \\
\hline white-collar & $-0.023 *$ & -1.75 & $0.199 * *$ & 2.25 \\
\hline blue-collar & -0.007 & -0.53 & -0.057 & -0.70 \\
\hline no previous employment & 0.115 & 1.40 & $-0.366^{*}$ & -1.85 \\
\hline \multicolumn{5}{|l|}{ Industry } \\
\hline industry & -0.017 & -1.32 & 0.043 & 0.54 \\
\hline services & 0.014 & 1.13 & -0.026 & -0.37 \\
\hline no previous employment & 0.045 & 0.55 & -0.119 & -0.56 \\
\hline \multicolumn{5}{|l|}{ Sector of Employment } \\
\hline public sector & 0.002 & 0.13 & 0.024 & 0.19 \\
\hline private sector & -0.004 & -0.68 & 0.005 & 0.14 \\
\hline no previous employment & 0.065 & 0.78 & -0.138 & -0.65 \\
\hline
\end{tabular}


Table 3: Ceteris Paribus Wage and Unemployment Changes (ctd.)

\begin{tabular}{|c|c|c|c|c|}
\hline & \multicolumn{2}{|c|}{ Wage Regressions } & \multicolumn{2}{|c|}{ Unemployment Regressions } \\
\hline & $\left(\hat{\boldsymbol{\beta}}_{t+\tau}^{*}-\hat{\boldsymbol{\beta}}_{t}^{*}\right)$ & $t$-value & $\left(\hat{\gamma}_{t+\tau}^{*}-\hat{\gamma}_{t}^{*}\right)$ & $t$-value \\
\hline \multicolumn{5}{|l|}{ Bundesland } \\
\hline $\begin{array}{l}\text { Schleswig-Holstein or } \\
\text { Hamburg }\end{array}$ & -0.012 & -0.33 & -0.338 & -1.49 \\
\hline Niedersachsen or Bremen & 0.011 & 0.47 & -0.159 & -1.29 \\
\hline Nordrhein-Westfalen & 0.005 & 0.42 & 0.104 & 1.47 \\
\hline Hessen & -0.016 & -0.63 & 0.045 & 0.32 \\
\hline $\begin{array}{l}\text { Rheinland-Pfalz or } \\
\text { Saarland }\end{array}$ & 0.000 & -0.01 & -0.015 & -0.08 \\
\hline Baden-Württemberg & -0.001 & -0.04 & -0.082 & -0.88 \\
\hline Bayern & -0.001 & -0.06 & 0.092 & 0.89 \\
\hline Observations & \multicolumn{2}{|c|}{5,566} & \multicolumn{2}{|c|}{7,288} \\
\hline In likelihood & \multicolumn{2}{|c|}{$-6,276.32$} & \multicolumn{2}{|c|}{$-1,762.24$} \\
\hline$\sigma_{t} ; \sigma_{t+\tau} ; \rho_{W}$ or $\rho_{U}$ & \multicolumn{2}{|c|}{$0.626 ; 0.614 ; 0.752$} & \multicolumn{2}{|c|}{0.231} \\
\hline
\end{tabular}

Notes: Coefficient changes marked with two (one) asterisk(s) are significant at the 5 (10) per cent level.

The occupation, industry, and sector of employment variables are taken from the most recently available of the corresponding three previous waves. People with no previous employment conceptually build an extra category for each of these three dummy variable groups. Hence this variable is reported three times here, although it only appears once in the estimation.

Because of the specific sampling procedure of the GSOEP, dummy variables were added to control for the changing subsample (A, B, C, D) weights; original estimation output is available from the author upon request.

Both $\rho_{W}$ and $\rho_{U}$ are significantly different from zero.

Source: GSOEP; own calculations. 
Table 4: Classification of Contribution of Labour Market Characteristics to Relative Wage Behaviour According to Definition 3

\begin{tabular}{|c|c|c|c|}
\hline & $\begin{array}{l}\text { Contributing to a } \\
\text { relative wage } \\
\text { increase } \\
\left(\beta_{t+\tau, k}^{*}-\beta_{t, k}^{*}\right)>0\end{array}$ & $\begin{array}{l}\text { Contributing to a } \\
\text { constant relative } \\
\text { wage } \\
\left(\beta_{t+\tau, k}^{*}-\beta_{t, k}^{*}\right)=0\end{array}$ & $\begin{array}{l}\text { Contributing to a } \\
\text { relative wage } \\
\text { decrease } \\
\left(\beta_{t+\tau, k}^{*}-\beta_{t, k}^{*}\right)<0\end{array}$ \\
\hline $\begin{array}{l}\text { Contributing to a } \\
\text { relative unemployment } \\
\text { increase } \\
\left(\gamma_{t+\tau, k}^{*}-\gamma_{t, k}^{*}\right)>0\end{array}$ & $\begin{array}{l}\text { contributing to a } \\
\text { strong relative wage } \\
\text { rigidity dynamic: } \\
\text { none }\end{array}$ & $\begin{array}{l}\text { contributing to a } \\
\text { weak relative wage } \\
\text { rigidity dynamic in a } \\
\text { decreasing market: } \\
\text { - age: } \mathbf{1 6 - 2 5} \text { years } \\
\text { - occupation: } \\
\text { white-collar }\end{array}$ & $\begin{array}{c}\text { contributing to a } \\
\text { weak relative wage } \\
\text { adjustment dynamic } \\
\text { in a decreasing } \\
\text { market: } \\
\text { none }\end{array}$ \\
\hline $\begin{array}{l}\text { Contributing to a } \\
\text { constant relative } \\
\text { unemployment } \\
\left(\gamma_{t+\tau, k}^{*}-\gamma_{t, k}^{*}\right)=0\end{array}$ & $\begin{array}{l}\text { contributing to a } \\
\text { strong relative wage } \\
\text { adjustment dynamic } \\
\text { in an increasing } \\
\text { market: } \\
\text { - occupation: } \\
\text { professional }\end{array}$ & $\begin{array}{c}\text { contributing to a } \\
\text { relatively stable } \\
\text { market: } \\
\\
\text { - all not otherwise } \\
\text { mentioned } \\
\text { characteristics }\end{array}$ & $\begin{array}{l}\text { contributing to a } \\
\text { strong relative wage } \\
\text { adjustment dynamic } \\
\text { in a decreasing } \\
\text { market: } \\
\\
\text { - education: } \\
\text { 15-20 years }\end{array}$ \\
\hline $\begin{array}{l}\text { Contributing to a } \\
\text { relative unemployment } \\
\text { decrease } \\
\left(\gamma_{t+\tau, k}^{*}-\gamma_{t, k}^{*}\right)<0\end{array}$ & $\begin{array}{l}\text { contributing to a } \\
\text { weak relative wage } \\
\text { adjustment dynamic } \\
\text { in an increasing } \\
\text { market: } \\
\text { none }\end{array}$ & $\begin{array}{l}\text { contributing to a } \\
\text { weak relative wage } \\
\text { rigidity dynamic in } \\
\text { an increasing } \\
\text { market: } \\
\text { none }\end{array}$ & $\begin{array}{l}\text { contributing to a } \\
\text { relative wage } \\
\text { convergence } \\
\text { dynamic: }\end{array}$ \\
\hline
\end{tabular}

Note: Classifications are undertaken on the basis of separate $t$-tests with a size of 5 per cent, which corresponds to a level of 10 per cent (which is the upper bound of the true size) of the Bonferroni joint test (see e.g. Mittelhammer, Judge, and Miller, 2000, p. 73 f.).

Source: GSOEP; own calculations. 


\section{Conclusions}

This paper has investigated whether and in which sense the west German wage structure has been 'rigid' in the 1990s. A 'strong wage rigidity dynamic' ('wage push') is defined as a rising wage rate and a rising unemployment rate in a labour market. A 'weak wage rigidity dynamic in a decreasing market' is defined as a constant wage rate and a rising unemployment rate in a labour market. The analysis further distinguishes between rigidities related to average wage developments and those related to the wage structure.

In order to test the popular hypothesis that rising unemployment rates in Europe are related to rigidities of the wage structure (Krugman 1994), I propose a methodology which makes less restrictive identifying assumptions than some previous studies about changes in labour demand and labour supply. Different dimensions of skill are distinguished, like age (experience), education, occupation, and other labour market characteristics which may make labour heterogeneous.

The empirical analysis shows that the west German wage structure exhibited no 'strong relative rigidities' between 1992 and 1998. However, 'weak relative rigidities' are found for the characteristics young age and white-collar worker: the ceteris paribus analysis demonstrates that these groups experienced an increase in the unemployment likelihood but no change in the wage relative to the 'average person'. What do my results suggest for the validity of Krugman's hypothesis that 'the European unemployment problem and the U.S. inequality problem are two sides of the same coin' (Krugman, 1994, p. 37), namely a fall in the relative demand for lowskilled workers? Krugman's hypothesis implies that - in the face of falling demand - inflexible wages for the low-skilled in Europe have been responsible for rising unemployment rates for this group. The evidence for western Germany in the 1990s demonstrates that this is only partly true: considering different dimensions of skill (e.g. age (experience), education, occupation, and others), I find that there has been no ceteris paribus fall in the relative demand for low-educated and bluecollar workers in western Germany in the 1990s. Hence, the comparatively stable wage structure with respect to low educational achievement and blue-collar occupation seems to have been justified by market forces. Support for Krugman's hypothesis, on the other hand, is provided by the finding that the west German wage structure did not respond to a negative relative demand shock for young workers (who have little labour market experience). This has led to a ceteris paribus increase in relative unemployment for this group. 
Moreover, at a 'macroeconomic' level, one observes that average real wages as well as the average unemployment rate have risen in the 1990s. Thus, average wages have been 'strongly rigid' (as defined in this paper) during the observation period.

\section{References}

Abraham, K.G. and S.N. Houseman (1995): Earnings Inequality in Germany in: R.B. Freeman and L.F. Katz (eds.): Differences and Changes in Wage Structures. Chicago: The University of Chicago Press, 371-403.

Beissinger, T. and J. Möller (1998): Wage Flexibility and Employment Performance: A Microdata Analysis of Different Age-Education Groups for Germany, University of Regensburg Discussion Paper No. 307, Regensburg.

Blanchflower, D.G. and A.J. Oswald (1994): The Wage Curve, Cambridge, MA: MIT Press.

Blau, F.D. and L.M. Kahn (1996): International Differences in Male Wage Inequality: Institutions versus Market Forces, Journal of Political Economy 104: 791-837.

Blau, F.D. and L.M. Kahn (1999): Institutions and Laws in the Labor Market in: O.C. Ashenfelter and D. Card (eds.): Handbook of Labor Economics. Handbooks in Economics, Vol. 3A. Amsterdam: Elsevier, 1399-1461.

Bonin, H. and K.F. Zimmermann (2001): The Post-Unification German Labor Market in: R.T. Riphahn, D.J. Snower and K.F. Zimmermann (eds.): Employment Policy in Transition: The Lesson of German Integration for the Labor Market. Heidelberg: Springer, 8-30.

Boockmann, B. and V. Steiner (2000): Cohort Effects and the Returns to Education in West Germany, ZEW Discussion Paper No. 00-05, Mannheim.

Booth, A. (1995): The Economics of the Trade Union, Cambridge: Cambridge University Press.

Bound, J. and G. Johnson (1992): Changes in the Structure of Wages in the 1980s: An Evaluation of Alternative Explanations, American Economic Review 82: 371-392.

Büttner, T. and B. Fitzenberger (1998): Central Wage Bargaining and Local Wage Flexibility: Evidence from the Entire Wage Distribution, ZEW Discussion Paper No. 98-39, Mannheim. 
Card, D. (1995): The Wage Curve: A Review, Journal of Economic Literature 33: 785-799.

Card, D., F. Kramarz, and T. Lemieux (1999): Changes in the Relative Structure of Wages and Employment: A Comparison of the United States, Canada, and France, Canadian Journal of Economics 32: 843-877.

Carlin, W. and D. Soskice (1990): Macroeconomics and the Wage Bargain, Oxford: Oxford University Press.

Entorf, H. (1996): Strukturelle Arbeitslosigkeit in Deutschland: Mismatch, Mobilität und technologischer Wandel [Structural Unemployment in Germany: Mismatch, Mobility and Technological Change] in: B. Gahlen, H. Hesse and H.J. Ramser (eds.): Arbeitslosigkeit und Möglichkeiten ihrer Überwindung [Unemployment and Possibilities to Overcome It]. Tübingen: J.C.B. Mohr (Paul Siebeck), 139-170.

Falk, M. and B. Koebel (2001): A Dynamic Heterogeneous Labour Demand Model for German Manufacturing, Applied Economics 33: 339-348.

Fitzenberger, B. (1999): Wages and Employment Across Skill Groups, An Analysis for West Germany, Heidelberg: Physica/Springer.

Fitzenberger, B. and W. Franz (1998): Flexibilität der qualifikatorischen Lohnstruktur und Lastverteilung der Arbeitslosigkeit: Eine ökonometrische Analyse für Westdeutschland [Flexibility of the Qualification Wage Structure and the Distribution Unemployment: An Econometric Analysis for Western Germany] in: B. Gahlen, H. Hesse and H.J. Ramser (eds.): Zunehmende Ungleichheit? - Erklärungen und Konsequenzen [Increasing Inequality? - Explanations and Consequences]. Schriftenreihe des Wirtschaftswissenschaftlichen Seminars Ottobeuren, Vol. 27, Tübingen: J.C.B. Mohr (Paul Siebeck), 47-79.

Fitzenberger, B. and W. Franz (1999): Industry-Level Wage Bargaining: A Partial Rehabilitation The German Experience, Scottish Journal of Political Economy 46: 437-457.

Fitzenberger, B. and W. Franz (2000): Jobs. Jobs? Jobs! Orientierungshilfen für den Weg zu mehr Beschäftigung [Jobs. Jobs? Jobs! Orientation Assistance for the Way to Higher Employment], ZEW Discussion Paper No. 00-49, Mannheim.

FitzRoy, F. and M. Funke (1995): Capital-Skill Complementarity in West German Manufacturing, Empirical Economics 20: 651-665. 
Franz, W. (1999): Arbeitsmarktökonomik [Labour Economics], $4^{\text {th }}$ edition, Berlin: Springer.

Freeman, R.B. and L.F. Katz (1995): Differences and Changes in Wage Structures, Chicago: The University of Chicago Press.

Freeman, R.B. and R. Schettkat (1999): The Role of Wage and Skill Differences in US-German Employment Differences, Jahrbücher für Nationalökonomie und Statistik 219: 49-66.

Freeman, R. and R. Schettkat (2000): Skill Compression, Wage Differentials and Employment: Germany vs. the US, NBER Working Paper No. 7610, Cambridge, MA.

Gottschalk, P. and T.M. Smeeding (1997): Cross-National Comparisons of Earnings and Income Inequality, Journal of Economic Literature 35: 633-687.

Gourieroux, C., A. Monfort, and A. Trognon (1984): Pseudo Maximum Likelihood Methods: Theory, Econometrica 52: 681-700.

Greene, W.H. (2000): Econometric Analysis, Upper Saddle River: Prentice Hall.

Haisken-DeNew, J.P. and C.M. Schmidt (1997): Interindustry and Interregion Differentials: Mechanics and Interpretation, Review of Economics and Statistics 79: 516-521.

Juhn, C., K.M. Murphy and B. Pierce (1993): Wage Inequality and the Rise in Returns to Skill, Journal of Political Economy 101: 410-442.

Kahn, L.M. (2000): Wage Inequality, Collective Bargaining, and Relative Employment from 1985 to 1994: Evidence from Fifteen OECD Countries, Review of Economics and Statistics 82: 564-579.

Katz, L. and K. Murphy (1992): Changes in Relative Wages 1963-1987: Supply and Demand Factors, Quarterly Journal of Economics 107: 35-78.

Katz, L.F. and D.H. Autor (1999): Changes in Wage Structure and Earnings Inequality in: O.C. Ashenfelter and D. Card (eds.): Handbook of Labor Economics. Handbooks in Economics, Vol. 3A. Amsterdam: Elsevier, 1463-1555.

Krueger, A.B. and J-S. Pischke (1997): Observations and Conjectures on the U.S. Employment Miracle, NBER Working Paper No. 6146, Cambridge MA.

Krugman, P. (1994): Past and Prospective Causes of High Unemployment, Economic Review, Federal Reserve Bank of Kansas City, 23-43.

Lauer, C. and V. Steiner (2000): Returns to Education in West Germany - An Empirical Assessment, ZEW Discussion Paper No. 00-04, Mannheim. 
Leung, S., F., Yu, S. (1996): On the Choice Between Sample Selection and Two-Part Models, Journal of Econometrics 72: 197-229.

Maddala, G.S. (1983): Limited-Dependent and Qualitative Variables in Econometrics, Cambridge: Cambridge University Press.

Mittelhammer, R.C., G.G. Judge, and D.J. Miller (2000): Econometric Foundations, Cambridge: Cambridge University Press; the electronic chapters E1 - E3 can be found on the CDROM accompanying the book.

Möller, J. (1999): Changes of the Structure of Wages and Employment with Respect to Qualifications in Germany: An Empirical Analysis, Jahrbücher für Nationalökonomie und Statistik 219: 8-47.

Möller, J. (2000): Technological Change, Unemployment, and Recent Trends in Human Capital Formation: Impact on the German Wage Structure, in: M.A: Landesmann and K. Pichelmann (eds.): Unemployment in Europe, London: Macmillan.

Murphy, K.M. and F. Welch (1992): The Structure of Wages, Quarterly Journal of Economics 107: 285-326.

Nickell, S. (1997): Unemployment and Labor Market Rigidities: Europe versus North America, Journal of Economic Perspectives 11: 55-74.

Nickell, S. (1998): Unemployment: Question and Some Answers, Economic Journal 108: 802-816.

Nickell, S. and B. Bell (1995): The Collapse in Demand for the Unskilled and Unemployment across the OECD, Oxford Review of Economic Policy 11: 40-62.

Nickell, S. and B. Bell (1996): Changes in the Distribution of Wages and Unemployment in OECD Countries, American Economic Review Papers and Proceedings 86: 302-321.

OECD (1996): Employment Outlook, July 1996, Paris: OECD.

Poirier, D.J. (1995): Intermediate Statistics and Econometrics, Cambridge, MA: MIT Press.

Puhani, P.A. (2000a): The Heckman Correction for Sample Selection and Its Critique, Journal of Economic Surveys 14: 53-68. 
Puhani, P.A. (2000b): On the Identification of Relative Wage Rigidity Dynamics, A Proposal for a Methodology on Cross-Section Data and Empirical Evidence for Poland in Transition, CEPR Discussion Paper No. 2670 (2001), London; IRISS Working Paper No. 2000-11, Luxembourg; IZA Discussion Paper No. 226, Bonn; The William Davidson Institute Working Paper No. 343, Ann Arbor; University of St. Gallen Economics Discussion Paper No. 2000-22; ZEW Discussion Paper No. 00-56, Mannheim.

Siebert, H. (1997): Labor Market Rigidities: At the Root of Unemployment in Europe, Journal of Economic Perspectives 11: 37-54.

Statistisches Bundesamt (2000): Statistisches Jahrbuch 2000 für die Bundesrepublik Deutschand [Statistical Yearbook of the Federal Republic of Germany], Stuttgart: Metzler-Poeschel.

Steiner, V. and R. Mohr (1998): Industrial Change, Stability of Relative Earnings, and Substitution of Unskilled Labor in West Germany, ZEW Discussion Paper No. 98-22, Mannheim.

Steiner, V. and Wagner, K. (1997): Relative Earnings and Demand for Unskilled Labor in West German Manufacturing, ZEW Discussion Paper No. 97-17, Mannheim, published in: S. Black (ed.): Globalization, Technological Change, and the Welfare State, Boston: Kluwer Academic Publishers.

Steiner, V. and Wagner, K. (1998): Has Earnings Inequality in Germany Changed in the 1980s?, Zeitschrift für Wirtschafts- und Sozialwissenschaften 118: 29-59.

Yun, M.-S. (2000): Decomposition Analysis for a Binary Choice Model, IZA Discussion Paper No. 145 , Bonn.

Zimmermann, V. (2000): Arbeitsmarktprobleme Jugendlicher, Eine empirische Untersuchung ihres Weges in die Beschäftigung [Youth Labour Market Problems: An Empirical Investigation of their Way into Employment], Baden-Baden: Nomos. 


\section{Appendix}

\section{A. Coefficient Transformation and Interpretation}

\section{Transformation of the Dummy Variable Coefficients}

This section is largely a reproduction and partly an adaptation of material in Puhani (2000b). Adapting the suggestion by Haisken-DeNew and Schmidt (1997), the transformation of regression coefficients $\boldsymbol{\beta}_{t}$ and $\boldsymbol{\gamma}_{t}$ (which include zeros for base categories of dummy variables and indicate the ceteris paribus deviation of the dependent variable when in the corresponding rather than the base category) to coefficients $\boldsymbol{\beta}_{t}^{*}$ and $\boldsymbol{\gamma}_{t}^{*}$, which indicate the corresponding deviation from the category mean $\overline{\mathbf{x}}$, is undertaken in the following way (including corresponding variancecovariance matrices):

$$
\begin{gathered}
\boldsymbol{\beta}_{t}^{*}=\left(\mathbf{I}-\mathbf{W}_{\boldsymbol{\beta}}\right) \boldsymbol{\beta}_{t} ; \boldsymbol{\gamma}_{t}^{*}=\left(\mathbf{I}-\mathbf{W}_{\gamma}\right) \boldsymbol{\gamma}_{t} \\
V\left(\boldsymbol{\beta}_{t}^{*}\right)=\left(\mathbf{I}-\mathbf{W}_{\boldsymbol{\beta}}\right) V\left(\boldsymbol{\beta}_{t}\right)\left(\mathbf{I}-\mathbf{W}_{\boldsymbol{\beta}}\right)^{\prime} ; V\left(\boldsymbol{\gamma}_{t}^{*}\right)=\left(\mathbf{I}-\mathbf{W}_{\gamma_{t}}\right) V(\boldsymbol{\gamma})\left(\mathbf{I}-\mathbf{W}_{\gamma}\right)^{\prime}
\end{gathered}
$$

with I the identity matrix and

$$
\mathbf{W}_{\boldsymbol{\beta}}=\left[\begin{array}{cccccccccccc}
0 & -w_{\beta_{11}} & \cdots & -w_{\beta_{1 D_{1}}} & \cdots & -w_{\beta_{l 1}} & \cdots & -w_{\beta_{D_{l}}} & \cdots & -w_{\beta_{L 1}} & \cdots & -w_{\beta_{L D_{L}}} \\
0 & w_{\beta_{11}} & \cdots & w_{\beta_{1 D_{1}}} & \mathbf{0} & 0 & \cdots & & \mathbf{0} & \cdots & & 0 \\
\vdots & \vdots & & \vdots & \vdots & \vdots & & & & & & \vdots \\
& w_{\beta_{11}} & \cdots & w_{\beta_{1 D_{1}}} & \mathbf{0} & 0 & \cdots & & & & & \\
\mathbf{0} & \cdots & & \mathbf{0} & \ddots & \mathbf{0} & \cdots & & \mathbf{0} & \cdots & & \mathbf{0} \\
\vdots & \cdots & & 0 & \mathbf{0} & w_{\beta_{l 1}} & \cdots & w_{\beta_{I D_{k}}} & \mathbf{0} & \cdots & & 0 \\
& & & & \vdots & \vdots & & \vdots & \vdots & & & \vdots \\
& \cdots & & 0 & \mathbf{0} & w_{\beta_{l 1}} & \cdots & w_{\beta_{I D_{l}}} & \mathbf{0} & \cdots & & 0 \\
\mathbf{0} & \cdots & & & \vdots & & & \mathbf{0} & \ddots & \mathbf{0} & \cdots & \mathbf{0} \\
\vdots & \cdots & & & & & & & \mathbf{0} & w_{\beta_{L 1}} & \cdots & w_{\beta_{L D_{L}}} \\
& & & & & & & & \vdots & \vdots & & \vdots \\
0 & \cdots & & & \mathbf{0} & \cdots & & & \mathbf{0} & w_{\beta_{L 1}} & \cdots & w_{\beta_{L D_{L}}}
\end{array}\right]
$$

such that 


$$
\sum_{d=1}^{D_{l}} w_{\beta_{l d}}=1 \quad \forall l
$$

where $l$ denotes the type of dummy variable group (e.g. age) for which $D_{l}$ different (e.g. age) categories exist. The bold $\mathbf{0} \mathrm{s}$ in $\mathbf{W}_{\boldsymbol{\beta}}$ refer to matrices containing only zeros. Note that in some cases displayed above, the $\mathbf{0} \mathrm{s}$ must be row vectors.

As defined, the first element of the $\boldsymbol{\beta}_{t}^{*}$ vector has to be the coefficient of the constant. For the weight $w_{\beta_{l d}}$ I choose the sample share of observations in category $d$ within the dummy variable group $l$ at time $t$, i.e. $w_{\beta_{l d}}=\bar{x}_{l, d, t}$. The matrix $\mathbf{I}-\mathbf{W}_{\boldsymbol{\beta}}$ thus transforms the coefficient of the constant to the expected value of the (underlying) dependent variable for the reference market, $E(\cdot \mid \overline{\mathbf{x}})$, which may be seen as an approximation of the sample mean of the (underlying) dependent variable. The elements of the thus defined coefficient vector $\boldsymbol{\beta}_{t}^{*}$ satisfy

$$
\sum_{d=1}^{D_{l}} w_{\beta_{l d}} \beta_{l, d, t}^{*}=0 \quad \forall l, t .
$$

$\gamma_{t}^{*}$ is defined analogously. I use the means of the 1992 wave $\bar{x}_{l, d, t}$ for both the transformations in $1992(t)$ and $1998(t+\tau)$ as weights $w_{\beta_{l d}}$, because constant weights need to be chosen to identify wage and unemployment dynamics for a labour market relative to a constant reference level (which is $\overline{\mathbf{x}}_{t}$ in this case).

As mentioned in Section 3.2 and outlined in this Appendix below, I am interested in the changes of the transformed coefficients, i.e.:

$$
\left(\boldsymbol{\beta}_{t+\tau}^{*}-\boldsymbol{\beta}_{t}^{*}\right) ;\left(\gamma_{t+\tau}^{*}-\gamma_{t}^{*}\right)
$$

with variance-covariance matrices

$$
\begin{aligned}
& V\left(\boldsymbol{\beta}_{t+\tau}^{*}-\boldsymbol{\beta}_{t}^{*}\right)=V\left(\boldsymbol{\beta}_{t+\tau}^{*}\right)+V\left(\boldsymbol{\beta}_{t}^{*}\right)-\operatorname{Cov}\left(\boldsymbol{\beta}_{t}^{*}, \boldsymbol{\beta}_{t+\tau}^{*}\right)-\operatorname{Cov}\left(\boldsymbol{\beta}_{t}^{*}, \boldsymbol{\beta}_{t+\tau}^{*}\right)^{\prime} \\
& V\left(\boldsymbol{\gamma}_{t+\tau}^{*}-\boldsymbol{\gamma}_{t}^{*}\right)=V\left(\boldsymbol{\gamma}_{t+\tau}^{*}\right)+V\left(\boldsymbol{\gamma}_{t}^{*}\right)-\operatorname{Cov}\left(\boldsymbol{\gamma}_{t}^{*}, \boldsymbol{\gamma}_{t+\tau}^{*}\right)-\operatorname{Cov}\left(\boldsymbol{\gamma}_{t}^{*}, \boldsymbol{\gamma}_{t+\tau}^{*}\right)^{\prime}
\end{aligned}
$$


where the covariance matrices $\operatorname{Cov}\left(\boldsymbol{\beta}_{t}^{*}, \boldsymbol{\beta}_{t+\tau}^{*}\right)$ and $\operatorname{Cov}\left(\boldsymbol{\gamma}_{t}^{*}, \boldsymbol{\gamma}_{t+\tau}^{*}\right)$ can be retrieved from the SURtype maximum likelihood estimates described in Section 3.2. Note that $\operatorname{Cov}\left(\boldsymbol{\beta}_{t}^{*}, \boldsymbol{\beta}_{t+\tau}^{*}\right)$ and $\operatorname{Cov}\left(\gamma_{t}^{*}, \gamma_{t+\tau}^{*}\right)$ are not standard variance-covariance matrices, but symmetric matrices containing the covariances of the elements of the vectors $\boldsymbol{\beta}_{t}^{*}, \boldsymbol{\beta}_{t+\tau}^{*}$ and $\gamma_{t}^{*}, \gamma_{t+\tau}^{*}$, respectively. The elements on the diagonals, for example, are $\operatorname{Cov}\left(\beta_{t, k}^{*}, \beta_{t+\tau, k}^{*}\right)$ and $\operatorname{Cov}\left(\gamma_{t, k}^{*}, \gamma_{t+\tau, k}^{*}\right)$, respectively. Estimation results are presented and discussed in Section 4.2.

\section{Interpretation of the Transformed Coefficients}

The following parameterisations shall be given:

$$
\begin{gathered}
E\left(\ln w_{t} \mid \mathbf{x}\right)=\boldsymbol{\beta}_{t}^{\prime} \mathbf{x} \Leftrightarrow E\left(w_{t} \mid \mathbf{x}\right)=\exp \left\{\boldsymbol{\beta}_{t}^{\prime} \mathbf{x}+0.5 \times \sigma_{t}^{2}\right\} \\
E\left(u_{t} \mid \mathbf{x}\right)=\Phi\left(\gamma_{t}^{\prime} \mathbf{x}\right)
\end{gathered}
$$

where $\sigma_{t}^{2}=\operatorname{Var}\left(\ln w_{t} \mid \mathbf{x}\right)$, and $\Phi(\cdot)$ denotes the cumulative distribution function of the standard normal distribution (see e.g. Mittelhammer, Judge, and Miller, 2000, Chapter E1, for the expected value of the log-normal distribution). $E\left(w_{\tau} \mid \mathbf{x}\right)=\exp \left\{\boldsymbol{\beta}_{\tau}^{\prime} \mathbf{x}+0.5 \times \sigma_{\tau}^{2}\right\}$ and $E\left(u_{\tau} \mid \mathbf{x}\right)=\Phi\left(\gamma_{\tau}^{\prime} \mathbf{x}\right)$ can be approximated by a first-order Taylor expansion around $\left(\boldsymbol{\beta}_{t}, \sigma_{t}^{2}\right)$ and $\left(\boldsymbol{\gamma}_{t}\right)$, respectively. Relative wage and unemployment dynamics $\left[E\left(w_{t+\tau}-w_{t} \mid \mathbf{x}\right)-E\left(w_{t+\tau}-w_{t} \mid \overline{\mathbf{x}}\right)\right]$ and $\left[E\left(u_{t+\tau}-u_{t} \mid \mathbf{x}\right)-E\left(u_{t+\tau}-u_{t} \mid \overline{\mathbf{x}}\right)\right]$ can then be expressed as follows (see also Yun, 2000, for the probit case):

$$
\begin{aligned}
E\left(w_{t+\tau}-w_{t} \mid \mathbf{x}\right)- & E\left(w_{t+\tau}-w_{t} \mid \overline{\mathbf{x}}\right) \approx \\
& {\left[\boldsymbol{\beta}_{t+\tau}-\boldsymbol{\beta}_{t}\right]^{\prime}\left[\mathbf{x} \exp \left\{\boldsymbol{\beta}_{t}^{\prime} \mathbf{x}+0.5 \times \sigma_{t}^{2}\right\}-\overline{\mathbf{x}} \exp \left\{\boldsymbol{\beta}_{t}^{\prime} \overline{\mathbf{x}}+0.5 \times \sigma_{t}^{2}\right\}\right]+} \\
& 0.5 \times\left[\sigma_{t+\tau}^{2}-\sigma_{t}^{2}\right]\left[\exp \left\{\boldsymbol{\beta}_{t}^{\prime} \mathbf{x}+0.5 \times \sigma_{t}^{2}\right\}-\exp \left\{\boldsymbol{\beta}_{t}^{\prime} \overline{\mathbf{x}}+0.5 \times \sigma_{t}^{2}\right\}\right]
\end{aligned}
$$


$E\left(u_{t+\tau}-u_{t} \mid \mathbf{x}\right)-E\left(u_{t+\tau}-u_{t} \mid \overline{\mathbf{x}}\right) \approx$

$$
\left[\gamma_{t+\tau}-\gamma_{t}\right]^{\prime}\left[\mathbf{x} \phi\left(\gamma_{t}^{\prime} \mathbf{x}\right)-\overline{\mathbf{x}} \phi\left(\gamma_{t}^{\prime} \overline{\mathbf{x}}\right)\right]
$$

Writing in terms of sums instead of matrix notation one gets

$$
\begin{gathered}
E\left(w_{t+\tau}-w_{t} \mid \mathbf{x}\right)-E\left(w_{t+\tau}-w_{t} \mid \overline{\mathbf{x}}\right) \approx \\
\sum_{k}\left[\beta_{t+\tau, k}-\beta_{t, k}\right]\left[x_{k} \exp \left\{\boldsymbol{\beta}_{t}^{\prime} \mathbf{x}+0.5 \times \sigma_{t}^{2}\right\}-\bar{x}_{k} \exp \left\{\boldsymbol{\beta}_{t}^{\prime} \overline{\mathbf{x}}+0.5 \times \sigma_{t}^{2}\right\}\right]+ \\
0.5 \times\left[\sigma_{t+\tau}^{2}-\sigma_{t}^{2}\right]\left[\exp \left\{\boldsymbol{\beta}_{t}^{\prime} \mathbf{x}+0.5 \times \sigma_{t}^{2}\right\}-\exp \left\{\boldsymbol{\beta}_{t}^{\prime} \overline{\mathbf{x}}+0.5 \times \sigma_{t}^{2}\right\}\right] \\
E\left(u_{t+\tau}-u_{t} \mid \mathbf{x}\right)-E\left(u_{t+\tau}-u_{t} \mid \overline{\mathbf{x}}\right) \approx \\
\sum_{k}\left[\gamma_{t+\tau, k}-\gamma_{t, k}\right]\left[x_{k} \phi\left(\gamma_{t}^{\prime} \mathbf{x}\right)-\bar{x}_{k} \phi\left(\gamma_{t}^{\prime} \overline{\mathbf{x}}\right)\right]
\end{gathered}
$$

where $k$ denotes an element of the $\boldsymbol{\beta}, \boldsymbol{\gamma}$, or $\mathbf{x}$ vectors. In my case, there are only dummy variables contained in $\mathbf{x}$. Assume that one has $L$ different sets of dummy variables each of which contains $D_{l}$ categories. The standard estimation procedure is to set the coefficient of one category (the base category) to zero. A specific coefficient then states the deviation of the expected value of the dependent variable of the respective category from the one of the base category. An alternative to this procedure is to present coefficients for each category such that they fulfil $\sum_{d=1}^{D_{l}} \beta_{l, d, t}^{*} \bar{x}_{l, d, t}=0 \quad \forall l$ and $\sum_{d=1}^{D_{l}} \beta_{l, d, t+\tau}^{*} \bar{x}_{l, d, t}=0 \quad \forall l$ (see Haisken-DeNew and Schmidt, 1997, and this Appendix above). This presentation contains exactly the same information, but the transformed coefficients $\beta_{l, d, t}^{*}$ and $\beta_{l, d, t+\tau}^{*}$ now state the deviation of the expected value of the dependent variable of the respective category from a hypothetical reference $\overline{\mathbf{x}}$ which in my case takes on the value of the mean at time $t, \overline{\mathbf{x}}=\overline{\mathbf{x}}_{t}$, for all categories of the respective dummy variable set. The $\gamma_{l, d, t}^{*}$ and $\gamma_{l, d, t+\tau}^{*}$ coefficients are obtained analogously. One can thus write

$$
\begin{aligned}
& E\left(w_{t+\tau}-w_{t} \mid \mathbf{x}\right)- E\left(w_{t+\tau}-w_{t} \mid \overline{\mathbf{x}}\right) \approx \\
& \sum_{k}\left[\beta_{t+\tau, k}^{*}-\beta_{t, k}^{*}\right]\left[x_{k} \exp \left\{\boldsymbol{\beta}_{t}^{* \prime} \mathbf{x}+0.5 \times \sigma_{t}^{2}\right\}-\bar{x}_{k} \exp \left\{\boldsymbol{\beta}_{t}^{* \prime} \overline{\mathbf{x}}+0.5 \times \sigma_{t}^{2}\right\}\right]+ \\
& 0.5 \times\left[\sigma_{t+\tau}^{2}-\sigma_{t}^{2}\right]\left[\exp \left\{\boldsymbol{\beta}_{t}^{* \prime} \mathbf{x}+0.5 \times \sigma_{t}^{2}\right\}-\exp \left\{\boldsymbol{\beta}_{t}^{* \prime} \overline{\mathbf{x}}+0.5 \times \sigma_{t}^{2}\right\}\right]
\end{aligned}
$$


$E\left(u_{t+\tau}-u_{t} \mid \mathbf{x}\right)-E\left(u_{t+\tau}-u_{t} \mid \overline{\mathbf{x}}\right) \approx$

$$
\sum_{k}\left[\gamma_{t+\tau, k}^{*}-\gamma_{t, k}^{*}\right]\left[x_{k} \phi\left(\gamma_{t}^{* \prime} \mathbf{x}\right)-\bar{x}_{k} \phi\left(\gamma_{t}^{* \prime} \overline{\mathbf{x}}\right)\right]
$$

Due to the transformation of the coefficient vectors (described in this Appendix above), one has

$$
\sum_{k} \beta_{t, k}^{*} \bar{x}_{k}=\beta_{t, 0}^{*}+\sum_{l=1}^{L} \underbrace{\sum_{d=1}^{D_{l}} \beta_{t, l, d}^{*} \bar{x}_{l, d}}_{=0}=\beta_{t, 0}^{*} \text { and } \sum_{k} \gamma_{t, k}^{*} \bar{x}_{k}=\gamma_{t, 0}^{*}+\sum_{l=1}^{L} \underbrace{\sum_{d=1}^{D_{l}} \gamma_{t, l, d}^{*} \bar{x}_{l, d}}_{=0}=\gamma_{t, 0}^{*} \forall t
$$

where $\beta_{t, 0}^{*}$ and $\gamma_{t, 0}^{*}$ are the transformed coefficients of the constants. Therefore,

$$
\begin{aligned}
& E\left(w_{t+\tau}-w_{t} \mid \mathbf{x}\right)-E\left(w_{t+\tau}-w_{t} \mid \overline{\mathbf{x}}\right) \approx \\
& \sum_{k \neq 0}\left[\beta_{t+\tau, k}^{*}-\beta_{t, k}^{*}\right]\left[x_{k} \exp \left\{\boldsymbol{\beta}_{t}^{* \prime} \mathbf{x}+0.5 \times \sigma_{t}^{2}\right\}\right]-\underbrace{\sum_{k \neq 0}\left[\beta_{t+\tau, k}^{*}-\beta_{t, k}^{*}\right]\left[\bar{x}_{k} \exp \left\{\boldsymbol{\beta}_{t}^{* \prime} \overline{\mathbf{x}}+0.5 \times \sigma_{t}^{2}\right\}\right]}_{=0}+ \\
& {\left[\beta_{t+\tau, 0}^{*}-\beta_{t, 0}^{*}\right]\left[\exp \left\{\boldsymbol{\beta}_{t}^{* \prime} \mathbf{x}+0.5 \times \sigma_{t}^{2}\right\}-\exp \left\{\boldsymbol{\beta}_{t}^{* \prime} \overline{\mathbf{x}}+0.5 \times \sigma_{t}^{2}\right\}\right]+} \\
& 0.5 \times\left[\sigma_{t+\tau}^{2}-\sigma_{t}^{2}\right]\left[\exp \left\{\boldsymbol{\beta}_{t}^{* \prime} \mathbf{x}+0.5 \times \sigma_{t}^{2}\right\}-\exp \left\{\boldsymbol{\beta}_{t}^{* \prime} \mathbf{x}+0.5 \times \sigma_{t}^{2}\right\}\right] \\
& E\left(u_{t+\tau}-u_{t} \mid \mathbf{x}\right)-E\left(u_{t+\tau}-u_{t} \mid \overline{\mathbf{x}}\right) \approx \\
& \sum_{k \neq 0}\left[\gamma_{t+\tau, k}^{*}-\gamma_{t, k}^{*}\right] x_{k} \phi\left(\gamma_{t}^{*,} \mathbf{x}\right)-\underbrace{\sum_{k \neq 0}\left[\gamma_{t+\tau, k}^{*}-\gamma_{t, k}^{*}\right] \bar{x}_{k} \phi\left(\gamma_{t}^{*} \overline{\mathbf{x}}\right)}_{=0}+ \\
& {\left[\gamma_{t+\tau, 0}^{*}-\gamma_{t, 0}^{*}\right] \phi\left(\gamma_{t}^{* \prime} \mathbf{x}\right)-\left[\gamma_{t+\tau, 0}^{*}-\gamma_{t, 0}^{*}\right] \phi\left(\gamma_{t}^{* \prime} \overline{\mathbf{x}}\right)}
\end{aligned}
$$

If a labour market has characteristic $x_{k}$, then $x_{k}=1$ (due to the dummy variable specification). It follows that the terms $\sum_{k \neq 0}\left[\beta_{t+\tau, k}^{*}-\beta_{t, k}^{*}\right]\left[x_{k} \exp \left\{\boldsymbol{\beta}_{t}^{* \prime} \mathbf{x}+0.5 \times \sigma_{t}^{2}\right\}\right]$ and $\sum_{k \neq 0}\left[\gamma_{t+\tau, k}^{*}-\gamma_{t, k}^{*}\right] x_{k} \phi\left(\boldsymbol{\gamma}_{t}^{* \prime} \mathbf{x}\right)$ are always positive if $\left[\beta_{t+\tau, k}^{*}-\beta_{t, k}^{*}\right]$ and $\left[\gamma_{t+\tau, k}^{*}-\gamma_{t, k}^{*}\right]$ are positive, respectively. This is the result I want to show: it means that if $\left[\beta_{t+\tau, k}^{*}-\beta_{t, k}^{*}\right]$ is positive, then being in a labour market which has characteristic $x_{k}$ raises the expected relative wage change $\left[E\left(w_{t+\tau}-w_{t} \mid \mathbf{x}\right)-E\left(w_{t+\tau}-w_{t} \mid \overline{\mathbf{x}}\right)\right]$ (ceteris paribus). Similarly, if $\left[\gamma_{t+\tau, k}^{*}-\gamma_{t, k}^{*}\right]$ is positive, then being in a labour market which has characteristic $x_{k}$ raises the expected relative unemployment change 
$\left[E\left(u_{t+\tau}-u_{t} \mid \mathbf{x}\right)-E\left(u_{t+\tau}-u_{t} \mid \overline{\mathbf{x}}\right)\right]$ (ceteris paribus). Note that this statement only holds for the changes of the transformed coefficients $\left[\beta_{t+\tau, k}^{*}-\beta_{t, k}^{*}\right]$ and $\left[\gamma_{t+\tau, k}^{*}-\gamma_{t, k}^{*}\right]$. The interpretation of the changes of the untransformed dummy variable coefficients $\left[\beta_{t+\tau, k}-\beta_{t, k}\right]$ and $\left[\gamma_{t+\tau, k}-\gamma_{t, k}\right]$ would not be unambiguous. The key issue is that in order to obtain the effect of a variable $x_{k}$ on e.g. the relative wage dynamics with respect to a reference market, the $\beta_{k}$ coefficient has to be transformed in such a way that it states the difference in the expected log-wage between a person in category $x_{k}$ and the reference person. In common specifications of dummy variables, the reference person is in a pre-specified base category. As my reference person is a 'mean' $\overline{\mathbf{x}}$, I have to transform the dummy variable coefficients such that they state the differences in the expected values of the log-wage to this mean. This transformation is the one suggested by Haisken-DeNew and Schmidt (1997). 


\section{B. Graphical Illustration of Equation (1)}

\section{Figure A1: A Net Supply Shock and the Trade-Off Between the Wage Rate and Unemployment}

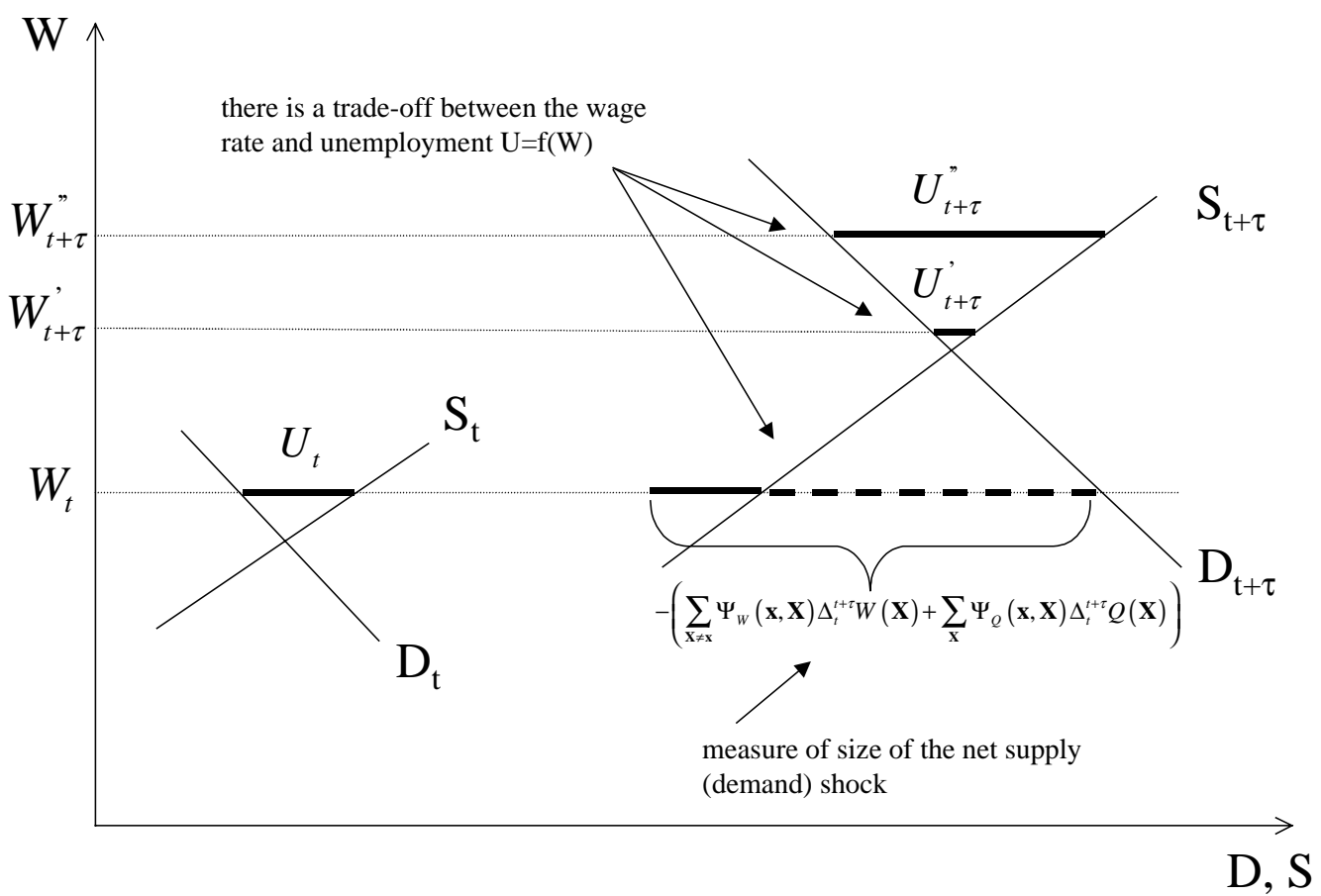

The figure illustrates the concepts of equation (1) in the text. The equation states the relationship between the change in the unemployment rate due to rigid wages $U_{\text {rigid wage rate }}$ in any labour market $\mathbf{x}$ and the change in the wage rate in this labour market as well as the changes in the net supply shift factors:

$$
\Delta_{t}^{t+\tau} U_{\text {rigid wage rate }}(\mathbf{x}) \approx \underbrace{\Psi_{W}(\mathbf{x}, \mathbf{x}) \Delta_{t}^{t+\tau} W(\mathbf{x})}_{\text {own wage effect }}+\underbrace{\sum_{\text {pross wage effects }}^{\sum_{\mathbf{X} \neq \mathbf{x}} \Psi_{W}(\mathbf{x}, \mathbf{X}) \Delta_{t}^{t+\tau} W(\mathbf{X})}+\underbrace{\sum_{\mathbf{X}} \Psi_{Q}(\mathbf{x}, \mathbf{X}) \Delta_{t}^{t+\tau} Q(\mathbf{X})}_{\text {purply shift effects }}}_{\text {net supply shift effects }}
$$

Net supply shift effects can only be observed directly if the wage rate is held constant. This is illustrated in a thought experiment in Figure A1. The graph displays the labour supply and demand schedules in a labour market $\mathbf{x}$ at times $t$ and $t+\tau$. Between these two points in time, both schedules shift to the right (one may think of this as a growing economy). However, at a constant wage rate, the increase in demand is larger than the increase in supply. Hence the net supply (demand) shift effect is negative (positive) such that unemployment would fall at a constant wage. For this reason, I term such a labour market an 'increasing market' (independent of the actual wage development). As can also be seen from the graph, any given demand-supply constellation presents 
a trade-off between the wage rate and unemployment. An increase in the wage rate will ceteris paribus raise unemployment, e.g. to $U_{t+\tau}^{\prime}$ or $U_{t+\tau}^{\prime}$. This is formalised by the own wage effect in equation (1).

\section{Relationship to the 'Wage Curve' Hypothesis}

This appendix shortly discusses how the approach taken in this paper relates to the 'wage curve' hypothesis, as this issue has been raised a number of times in seminars. An overview of the wage curve hypothesis can be found in the book by Blanchflower and Oswald (1994) and in the review article by Card (1995). The wage curve is primarily an empirical phenomenon: regressions of the logarithm of wages on the logarithm of local unemployment rates and other control variables have found a coefficient of about -0.1 on the logarithm of the local unemployment rate. This empirical correlation between local unemployment and wages is termed the 'wage curve'. A 'local' unemployment rate can refer to a region or an industry, but other definitions of local labour markets are conceivable. Although a number of theories can be proposed for the empirical finding of a wage curve, I will discuss here how the wage curve relates to my own framework.

As mentioned in Appendix B., there is - in the neoclassical model proposed in this paper - a tradeoff between the wage rate and unemployment for any demand-supply constellation in a labour market. Figure A2 below shows how this trade-off may be displayed for different demand-supply constellations (the trade-off need not be linear, of-course) in wage-unemployment space. I draw in this space, because this is where the wage curve is usually presented (see also Figure A2 for a presentation of a wage curve). Assume we are in a labour market which rests at an equilibrium $\left(W_{t}, U_{t}\right)$ and this labour market experiences positive net demand shocks. The results will we downward shifts in the wage-unemployment trade-off lines. The equilibria that we would observe corresponding to various shocks depends on where wages settle. It may well be possible that they settle on the 'wage curve' line and, in this case, one would observe the wage curve as a negative relationship between wages and unemployment. On the other hand, it is conceivable that there are no net demand shocks, but that the wage setting mechanism varies such that different points on a wage-unemployment trade-off line are chosen. In this case, one would observe a positive correlation between wages and unemployment.

As I do not model wage setting in this paper, my model is not incompatible with the existence of a wage curve (in the sense of a negative statistical correlation between wages and unemployment 
rates). However, I address a different question than the wage curve literature. Blanchflower and Oswald (1994, p. 6) suggest that the wage curve constitutes a 'measure of wage inflexibility'. Yet, from the perspective of the framework I use here, two remarks are important.

First, as Figure A2 illustrates, the change in observed unemployment is not necessarily a measure of the net demand shock a labour market experienced. Therefore the observed changes in the wage rate and unemployment do not indicate how wages react to shocks, as shocks cannot be straightforwardly measured unless the wage rate remains unchanged. In the face of this endogeneity of unemployment to wage setting, the wage curve can only be a measure of labour market inflexibility in this framework if further assumptions on the trade-off between the wage rate and unemployment are invoked (e.g. that the trade-offs are equal across all labour markets).

Second, the wage curve estimates only one parameter which describes the equilibrium locus of wages and unemployment. The notion is that this parameter is a summary measure of wage rigidity. I argue that this is not the correct interpretation if labour markets are heterogeneous in their reaction to shocks. This heterogeneity is the issue of interest in this paper, as illustrated in Figures A3 and A4. Figure A3 displays the nine (I to IX) different cases of the classification of wage behaviour and labour markets of Definition 1. The wage curve lies in quadrants III and VII and goes through point IX (which is the initial equilibrium on the wage curve). As shown in Figure A4, one may observe a wage curve, although some labour markets are perfectly flexible when shocked (i.e. they correspond to cases II and VI of Figure A3). These can even be the majority of labour markets and therefore the wage curve does not necessarily provide a summary measure of wage inflexibility!

My interest is in finding out which labour markets are flexible and which are rigid between two points of time $t$ and $t+\tau$. I argue that this is an interesting question from a policy perspective: I want to know where wages are rigid in the economy. As Figure A4 shows, the regression of wages on unemployment (i.e. the estimation of a wage curve) does not provide an answer to this question. 


\section{Figure A2: Shocks to a Labour Market and Potential Wage-Unemployment Outcomes}

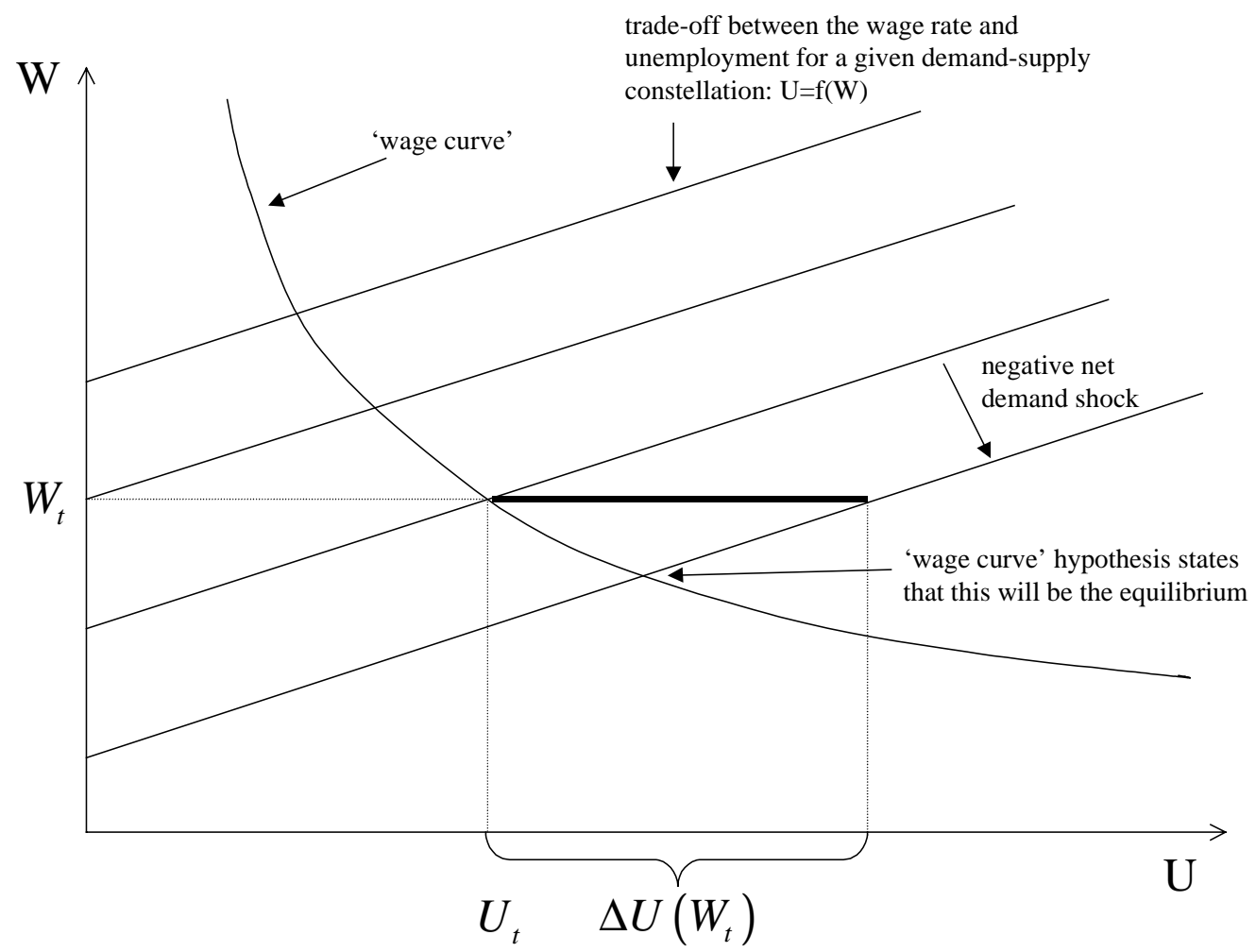

Figure A3: The Difference Between My Approach and the Attempt to Estimate a Wage Curve

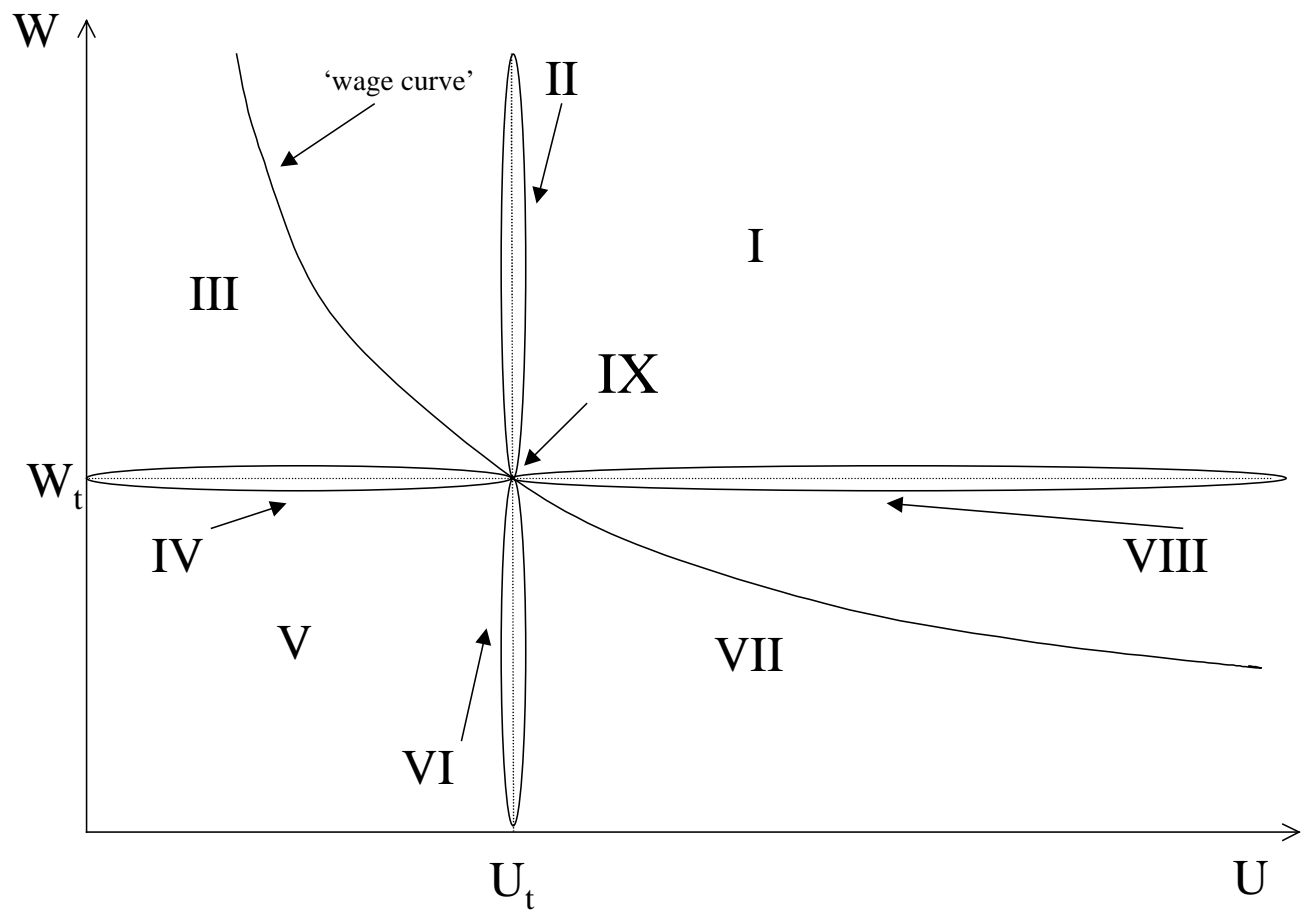

Note: The figure illustrates the classification of labour markets according to their position in wage unemployment space at time period $t+\tau$ when the equilibrium in period $t$ has been $\left(W_{t}, U_{t}\right)$. The Roman numbers refer to the following cases: quadrant I (strongly rigid - wage push), line II (strongly adjusting in an increasing market), quadrant III (weakly adjusting in an increasing 
market), line IV (weakly rigid in an increasing market), quadrant V (strongly converging), line VI (strongly adjusting in a decreasing market), quadrant VII (weakly adjusting in a decreasing market), line VIII (weakly rigid in a decreasing market), point IX (stable in a stable market).

Figure A4: Heterogeneity Which the 'Wage Curve' Cannot Explain

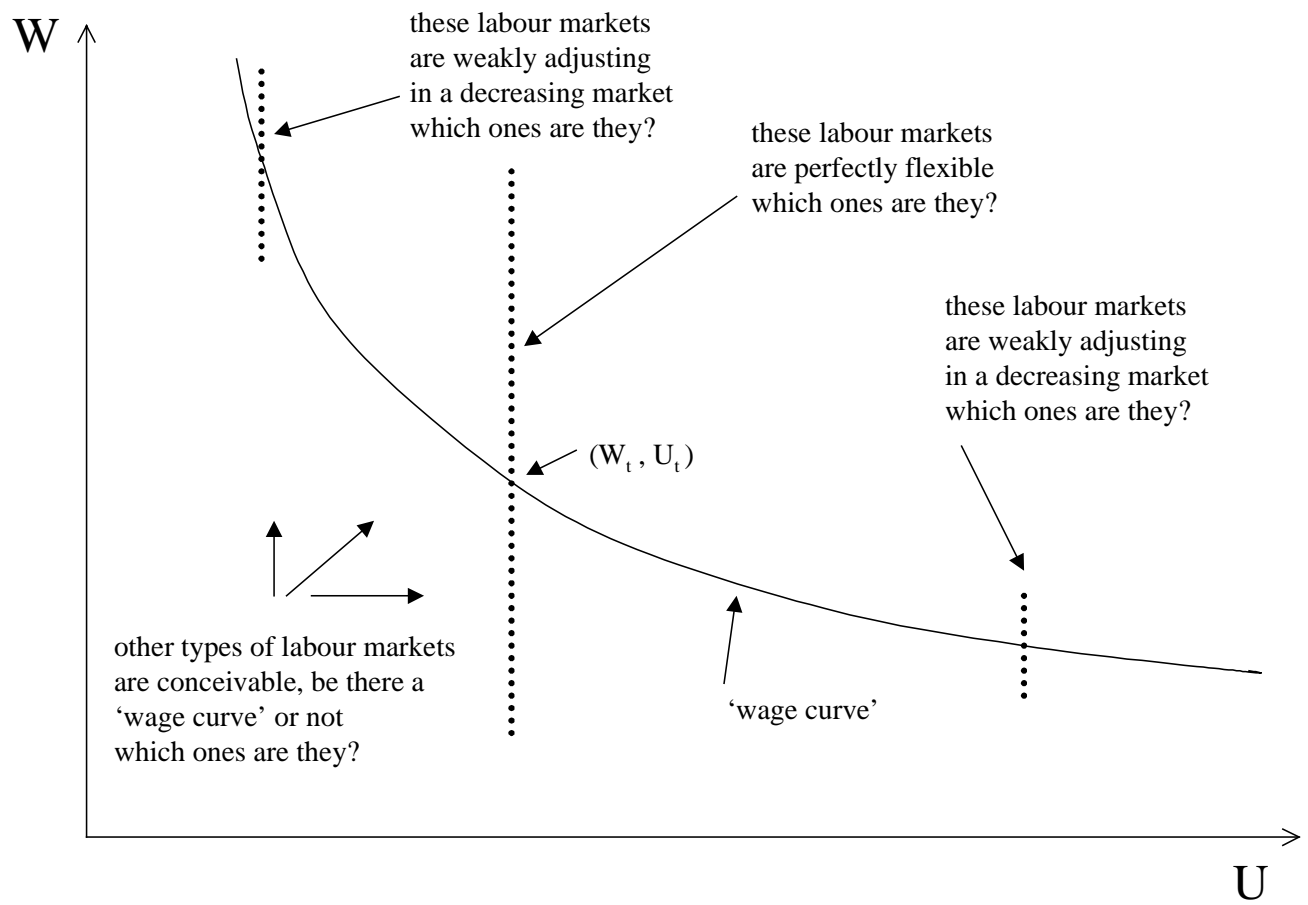

Note: The figure illustrates that even if regression analysis identifies a 'wage curve', the interesting question which labour markets are perfectly flexible and which ones not remains unanswered. 


\section{Data Appendix}

Table A1: Sample Sizes

\begin{tabular}{lc|ccccccc}
\hline \hline Equation & Year & $(1)$ & $(2)$ & $(3)$ & $(4)$ & $(5)$ & $(6)$ & $(7)$ \\
\hline Wage & 1992 & 5,517 & 4,632 & 4,621 & 4,446 & 4,360 & 4,243 & 4,206 \\
& 1998 & 6,007 & 5,105 & 5,087 & 4,370 & 4,303 & 4,120 & 4,069 \\
Unemployment & 1992 & 9,080 & 5,788 & 5,765 & 5,526 & 5,398 & 5,231 & 5,186 \\
& 1998 & 10,480 & 6,458 & 6,423 & 5,374 & 5,271 & 5,054 & 4,983 \\
\hline \hline
\end{tabular}

Notes: Observations not fulfilling the following criteria are successively eliminated from the sample: (1) number of employed people (wage equation) or people who report a labour force status (unemployment equation) in the corresponding wave; (2) number of observations with a reported hourly wage rate (wage equation) or number of people in the labour force (unemployment equation); (3) age between 16 and 65 years (inclusively); (4) observations are already observed in any of the three previous waves (to obtain occupation, industry, and sector of employment variables; see the discussion in Section 4.1); (5) observations report occupation, industry, and sector of employment; (6) observations do not belong to the categories occupation: manager or industry: agriculture; (7) observations have no other missings in the variables used for estimation.

Due to the panel nature of the GSOEP, there are common observations in the 1992 and 1998 waves. As a result, the total number of individuals in the wage (unemployment) equations is 5,556 (7,288).

Source: German Socio-Economic Panel (GSOEP); own calculations. 
Table A2: Sample Unemployment Rates

\begin{tabular}{|c|c|c|c|c|}
\hline & 1992 & 1994 & 1996 & 1998 \\
\hline Whole sample & 4.396 & 6.064 & 6.764 & 7.024 \\
\hline \multicolumn{5}{|l|}{ Age in years } \\
\hline $16-25$ & 5.818 & 12.990 & 13.350 & 13.938 \\
\hline $26-35$ & 4.812 & 7.009 & 6.804 & 7.332 \\
\hline $36-45$ & 3.810 & 3.967 & 5.822 & 6.391 \\
\hline $46-55$ & 3.682 & 3.575 & 4.524 & 4.145 \\
\hline $56-65$ & 3.676 & 1.632 & 3.491 & 4.464 \\
\hline \multicolumn{5}{|l|}{ Education in years } \\
\hline $0-8$ & 9.176 & 8.684 & 11.957 & 12.333 \\
\hline 9 & 5.426 & 9.558 & 8.459 & 11.273 \\
\hline $10-11$ & 3.563 & 5.675 & 5.872 & 6.575 \\
\hline $12-13$ & 5.663 & 5.423 & 7.981 & 6.692 \\
\hline 14 & 2.577 & 4.433 & 5.172 & 4.292 \\
\hline $15-20$ & 2.817 & 3.704 & 5.311 & 4.538 \\
\hline \multicolumn{5}{|l|}{ Gender } \\
\hline male & 3.364 & 5.909 & 6.189 & 6.627 \\
\hline female & 5.850 & 6.277 & 7.527 & 7.549 \\
\hline \multicolumn{5}{|l|}{ Occupation } \\
\hline professional & 1.551 & 3.581 & 2.978 & 2.113 \\
\hline white-collar & 1.625 & 3.790 & 3.688 & 4.593 \\
\hline blue-collar & 3.034 & 6.003 & 5.553 & 5.843 \\
\hline no previous employment & 35.736 & 29.242 & 33.703 & 39.080 \\
\hline \multicolumn{5}{|l|}{ Industry } \\
\hline industry & 2.514 & 5.398 & 4.801 & 4.957 \\
\hline services & 1.978 & 4.010 & 3.890 & 4.336 \\
\hline no previous employment & 35.736 & 29.242 & 33.703 & 39.080 \\
\hline \multicolumn{5}{|l|}{ Sector of Employment } \\
\hline public sector & 1.372 & 2.258 & 3.109 & 2.893 \\
\hline private sector & 2.500 & 5.441 & 4.682 & 5.157 \\
\hline no previous employment & 35.736 & 29.242 & 33.703 & 39.080 \\
\hline
\end{tabular}


Table A2: Sample Unemployment Rates (ctd.)

\begin{tabular}{lllll}
\hline & 1992 & 1994 & 1996 & 1998 \\
\hline $\begin{array}{l}\text { Bundesland } \\
\text { Schleswig-Holstein or }\end{array}$ & 4.641 & 4.274 & 6.122 & 4.206 \\
$\begin{array}{l}\text { Hamburg } \\
\text { Niedersachsen or Bremen }\end{array}$ & 5.263 & 6.491 & 7.078 & 7.465 \\
Nordrhein-Westfalen & 5.628 & 7.004 & 6.983 & 8.463 \\
Hessen & 3.591 & 5.313 & 6.872 & 7.173 \\
Rheinland-Pfalz or & 3.254 & 5.740 & 7.434 & 5.128 \\
Saarland & & & & \\
Baden-Württemberg & 4.087 & 6.143 & 6.436 & 6.392 \\
Bayern & 3.175 & 5.275 & 6.375 & 6.515 \\
\hline Observations & 5,186 & 4,931 & 5,411 & 4,983 \\
\hline \hline
\end{tabular}

Note: The occupation, industry, and sector of employment variables are taken from the most recently available of the corresponding three previous waves. People with no previous employment conceptually build an extra category for each of these three dummy variable groups. Hence this variable is reported three times here, although it only appears once in the estimation.

Note that changes in these figures over time are sensitive to changing shares of GSOEP subsamples. Labour force sample shares of subsamples A (people in households living in western Germany in 1984), B (foreigners of certain nationalities in western Germany), C (east Germans), and D (immigrants entering the country 1984-93) are 69.65, 29.93, 0.42, 0.00 per cent in 1992, 69.44, 28.92, 1.64, 0.00 per cent in 1994, 61.98, 23.64, 2.51, 11.86 per cent in 1996, and 64.10, $22.66,2.73,10.52$ per cent in 1998, respectively. The peak in the sample unemployment rate is in 1998 instead of 1997 (where the peak in the official figures occurs) even if subsample D is dropped. The empirical analysis controls for the changes in subsample weights by dummy variables.

Source: GSOEP; own calculations. 


\begin{tabular}{|c|c|c|c|c|}
\hline & \multicolumn{2}{|c|}{ Means Wage Regression } & \multicolumn{2}{|c|}{$\begin{array}{c}\text { Means Unemployment } \\
\text { Regression }\end{array}$} \\
\hline & 1992 & 1998 & 1992 & 1998 \\
\hline $\begin{array}{l}\text { In hourly wage rate; or } \\
\text { unemployed, respectively }\end{array}$ & 3.015 & 3.056 & 0.044 & 0.070 \\
\hline \multicolumn{5}{|l|}{ Age in years } \\
\hline $16-25$ & 0.173 & 0.116 & 0.176 & 0.124 \\
\hline $26-35$ & 0.274 & 0.331 & 0.272 & 0.326 \\
\hline $36-45$ & 0.255 & 0.268 & 0.248 & 0.267 \\
\hline $46-55$ & 0.224 & 0.197 & 0.225 & 0.194 \\
\hline $56-65$ & 0.074 & 0.088 & 0.079 & 0.090 \\
\hline \multicolumn{5}{|l|}{ Education in years } \\
\hline $0-8$ & 0.080 & 0.054 & 0.082 & 0.060 \\
\hline 9 & 0.120 & 0.088 & 0.124 & 0.096 \\
\hline $10-11$ & 0.549 & 0.520 & 0.541 & 0.513 \\
\hline $12-13$ & 0.115 & 0.159 & 0.119 & 0.156 \\
\hline 14 & 0.039 & 0.047 & 0.037 & 0.047 \\
\hline $15-20$ & 0.099 & 0.132 & 0.096 & 0.128 \\
\hline \multicolumn{5}{|l|}{ Gender } \\
\hline male & 0.594 & 0.578 & 0.585 & 0.569 \\
\hline female & 0.406 & 0.422 & 0.415 & 0.431 \\
\hline \multicolumn{5}{|l|}{ Occupation } \\
\hline professional & 0.144 & 0.183 & 0.137 & 0.171 \\
\hline white-collar & 0.387 & 0.412 & 0.380 & 0.402 \\
\hline blue-collar & 0.431 & 0.367 & 0.419 & 0.357 \\
\hline no previous employment & 0.038 & 0.038 & 0.064 & 0.070 \\
\hline \multicolumn{5}{|l|}{ Industry } \\
\hline industry & 0.488 & 0.438 & 0.468 & 0.421 \\
\hline services & 0.474 & 0.523 & 0.468 & 0.509 \\
\hline no previous employment & 0.038 & 0.038 & 0.064 & 0.070 \\
\hline \multicolumn{5}{|l|}{ Sector of Employment } \\
\hline public sector & 0.227 & 0.240 & 0.211 & 0.222 \\
\hline private sector & 0.735 & 0.722 & 0.725 & 0.708 \\
\hline no previous employment & 0.038 & 0.038 & 0.064 & 0.070 \\
\hline
\end{tabular}




\begin{tabular}{lcccc}
\hline & Means Wage Regression & \multicolumn{2}{c}{$\begin{array}{c}\text { Means Unemployment } \\
\text { Regression }\end{array}$} \\
& 1992 & 1998 & 1992 & 1998 \\
\hline $\begin{array}{l}\text { Bundesland } \\
\text { Schleswig-Holstein or }\end{array}$ & 0.046 & 0.044 & 0.046 & 0.043 \\
Hamburg & & & 0.106 & 0.129 \\
Niedersachsen or Bremen & 0.107 & 0.130 & 0.281 & 0.285 \\
Nordrhein-Westfalen & 0.274 & 0.276 & 0.107 & 0.095 \\
Hessen & 0.111 & 0.098 & 0.065 & 0.078 \\
Rheinland-Pfalz or & 0.067 & 0.079 & & 0.185 \\
Saarland & & & 0.212 & 0.185 \\
Baden-Württemberg & 0.209 & 0.188 & 0.182 & 4,983 \\
Bayern & 0.186 & 0.186 & 5,186 & \\
\hline Observations & 4,206 & 4,069 & & \\
\hline
\end{tabular}

Notes: The hourly wage rate is measured in 1998 Deutsche Marks. 1992 wages are adjusted by the consumer price index for western Germany (Statistisches Bundesamt, 2000).

The occupation, industry, and sector of employment variables are taken from the most recently available of the corresponding three previous waves. People with no previous employment conceptually build an extra category for each of these three dummy variable groups. Hence this variable is reported three times here, although it only appears once in the estimation.

Labour force sample shares of subsamples A (people in households living in western Germany in 1984), B (foreigners of certain nationalities in western Germany), C (east Germans), and D (immigrants entering the country 1984-93) are 69.65, 29.93, 0.42, 0.00 per cent in 1992 and 64.10, $22.66,2.73,10.52$ per cent in 1998 , respectively. The empirical analysis controls for the changes in subsample weights by dummy variables.

Due to the panel nature of the GSOEP, there are common observations in the 1992 and 1998 waves. As a result, the total number of individuals in the wage (unemployment) equations is 5,556 $(7,288)$.

Source: GSOEP; own calculations. 


\begin{tabular}{|c|c|c|c|c|}
\hline & \multicolumn{2}{|c|}{ Wage Regression } & \multicolumn{2}{|c|}{ Unemployment Regression } \\
\hline & $\hat{\boldsymbol{\beta}}_{t}^{*}$ & $t$-value & $\hat{\gamma}_{t}^{*}$ & $t$-value \\
\hline 1992 Sample Mean & $3.007 * *$ & 337.74 & $-2.061 * *$ & -39.11 \\
\hline \multicolumn{5}{|l|}{ Age in years } \\
\hline $16-25$ & $-0.362 * *$ & -17.61 & $-0.174 * *$ & -2.26 \\
\hline $26-35$ & 0.003 & 0.29 & $0.142 * *$ & 2.48 \\
\hline $36-45$ & $0.089 * *$ & 8.44 & -0.031 & -0.47 \\
\hline $46-55$ & $0.128 * *$ & 10.93 & 0.010 & 0.14 \\
\hline $56-65$ & $0.142 * *$ & 6.29 & -0.033 & -0.25 \\
\hline \multicolumn{5}{|l|}{ Education in years } \\
\hline $0-8$ & $-0.071 * *$ & -2.71 & $0.213^{* *}$ & 2.07 \\
\hline 9 & $-0.228 * *$ & -8.51 & 0.035 & 0.38 \\
\hline $10-11$ & 0.004 & 0.55 & -0.013 & -0.38 \\
\hline $12-13$ & -0.015 & -0.71 & 0.022 & 0.24 \\
\hline 14 & $0.116 * *$ & 3.61 & -0.104 & -0.49 \\
\hline $15-20$ & $0.285^{* *}$ & 11.34 & -0.139 & -0.97 \\
\hline \multicolumn{5}{|l|}{ Gender } \\
\hline male & $0.090 * *$ & 14.16 & $-0.091 * *$ & -2.77 \\
\hline female & $-0.132 * *$ & -14.16 & $0.127 * *$ & 2.77 \\
\hline \multicolumn{5}{|l|}{ Occupation } \\
\hline professional & $0.132 * *$ & 6.27 & -0.148 & -1.12 \\
\hline white-collar & $0.032 * *$ & 2.68 & $-0.321 * *$ & -4.53 \\
\hline blue-collar & $-0.024 * *$ & -1.96 & 0.062 & 0.97 \\
\hline no previous employment & $-0.558 * *$ & -9.79 & $1.810 * *$ & 11.67 \\
\hline \multicolumn{5}{|l|}{ Industry } \\
\hline industry & $0.093 * *$ & 8.02 & $-0.227 * *$ & -3.62 \\
\hline services & $-0.047 * *$ & -4.22 & -0.011 & -0.20 \\
\hline no previous employment & $-0.598 * *$ & -10.34 & $1.732 * *$ & 10.47 \\
\hline \multicolumn{5}{|l|}{ Sector of Employment } \\
\hline public sector & $0.071 * *$ & 4.49 & $-0.286 * *$ & -2.84 \\
\hline private sector & $0.010 * *$ & 1.96 & $-0.065 * *$ & -2.06 \\
\hline no previous employment & $-0.620 * *$ & -10.71 & $1.673 * *$ & 10.11 \\
\hline
\end{tabular}


Table A4: Wage and Unemployment Structures 1992 (ctd.)

\begin{tabular}{lcccc}
\hline & \multicolumn{2}{c}{ Wage Regression } & \multicolumn{2}{c}{ Unemployment Regression } \\
& $\hat{\boldsymbol{\beta}}_{t}^{*}$ & $t$-value & $\hat{\boldsymbol{\gamma}}^{*}$ & $t$-value \\
\hline $\begin{array}{l}\text { Bundesland } \\
\text { Schleswig-Holstein or }\end{array}$ & 0.003 & 0.13 & 0.132 & 0.84 \\
$\begin{array}{l}\text { Hamburg } \\
\text { Niedersachsen or Bremen }\end{array}$ & $-0.047^{* *}$ & -2.29 & $0.211^{* *}$ & 2.15 \\
Nordrhein-Westfalen & -0.017 & -1.62 & 0.062 & 1.12 \\
Hessen & 0.028 & 1.45 & -0.088 & -0.80 \\
Rheinland-Pfalz or & -0.037 & -1.62 & -0.165 & -1.07 \\
Saarland & & & & -0.32 \\
Baden-Württemberg & 0.022 & 1.60 & -0.022 & -1.40 \\
Bayern & $0.024^{* *}$ & 1.85 & -0.116 & \\
\hline \hline
\end{tabular}

Notes: Coefficients marked with two (one) asterisk(s) are significant at the 5 (10) per cent level. The occupation, industry, and sector of employment variables are taken from the corresponding three previous waves. People with no previous employment conceptually build an extra category for each of these three dummy variable groups. As a consequence, this variable appears in each group of the occupation, industry, and sector of employment variables for the transformation of the coefficients as described in Appendix A., although it only appears once in the estimation. As mentioned in the text and Appendix A., the reference person is the 1992 Sample Mean $\overline{\mathbf{x}}_{t}$ also for the year 1998.

Source: GSOEP; own calculations. 


\begin{tabular}{|c|c|c|c|c|}
\hline & \multicolumn{2}{|c|}{ Wage Regression } & \multicolumn{2}{|c|}{ Unemployment Regression } \\
\hline & $\hat{\boldsymbol{\beta}}_{t+\tau}^{*}$ & $t$-value & $\hat{\gamma}_{t+\tau}^{*}$ & $t$-value \\
\hline 1992 Sample Mean & $3.049 * *$ & 305.26 & $-1.718 * *$ & -39.31 \\
\hline \multicolumn{5}{|l|}{ Age in years } \\
\hline $16-25$ & $-0.335^{* *}$ & -10.87 & $0.153 * *$ & 2.33 \\
\hline $26-35$ & -0.005 & -0.37 & 0.049 & 1.07 \\
\hline $36-45$ & $0.105 * *$ & 8.93 & 0.024 & 0.47 \\
\hline $46-55$ & $0.107 * *$ & 9.02 & $-0.155^{* *}$ & -2.34 \\
\hline $56-65$ & $0.120 * *$ & 6.05 & -0.146 & -1.34 \\
\hline \multicolumn{5}{|l|}{ Education in years } \\
\hline $0-8$ & $-0.092 * *$ & -3.13 & $0.167 *$ & 1.65 \\
\hline 9 & $-0.236^{* *}$ & -9.40 & $0.141 * *$ & 1.80 \\
\hline $10-11$ & 0.009 & 1.28 & -0.011 & -0.38 \\
\hline $12-13$ & 0.015 & 0.82 & -0.119 & -1.56 \\
\hline 14 & $0.158 * *$ & 4.88 & -0.139 & -0.91 \\
\hline $15-20$ & $0.233 * *$ & 9.58 & -0.061 & -0.59 \\
\hline \multicolumn{5}{|l|}{ Gender } \\
\hline male & $0.093 * *$ & 14.33 & -0.012 & -0.43 \\
\hline female & $-0.137 * *$ & -14.33 & 0.017 & 0.43 \\
\hline \multicolumn{5}{|l|}{ Occupation } \\
\hline professional & $0.185 * *$ & 9.05 & $-0.352 * *$ & -3.35 \\
\hline white-collar & 0.009 & 0.77 & $-0.123 * *$ & -2.30 \\
\hline blue-collar & $-0.031 * *$ & -2.66 & 0.005 & 0.09 \\
\hline no previous employment & $-0.443 * *$ & -7.09 & $1.444 * *$ & 11.67 \\
\hline \multicolumn{5}{|l|}{ Industry } \\
\hline industry & $0.075 * *$ & 6.73 & $-0.184 * *$ & -3.77 \\
\hline services & $-0.033 * *$ & -3.02 & -0.037 & -0.85 \\
\hline no previous employment & $-0.553 * *$ & -8.60 & $1.613 * *$ & 11.67 \\
\hline \multicolumn{5}{|l|}{ Sector of Employment } \\
\hline public sector & $0.073 * *$ & 4.65 & $-0.262 * *$ & -3.46 \\
\hline private sector & 0.006 & 1.15 & $-0.060 * *$ & -2.54 \\
\hline no previous employment & $-0.555 * *$ & -8.63 & $1.535 * *$ & 11.23 \\
\hline
\end{tabular}


Table A5: Wage and Unemployment Structures 1998 (ctd.)

\begin{tabular}{lcccc}
\hline & \multicolumn{2}{c}{ Wage Regression } & \multicolumn{2}{c}{ Unemployment Regression } \\
& $\hat{\boldsymbol{\beta}}_{t+\tau}^{*}$ & $t$-value & $\hat{\gamma}_{t+\tau}^{*}$ & $t$-value \\
\hline $\begin{array}{l}\text { Bundesland } \\
\text { Schleswig-Holstein or }\end{array}$ & -0.009 & -0.30 & -0.206 & -1.24 \\
Hamburg & & & \\
Niedersachsen or Bremen & $-0.036^{* *}$ & -1.98 & 0.052 & 0.67 \\
Nordrhein-Westfalen & -0.012 & -1.11 & $0.166^{* *}$ & 3.61 \\
Hessen & 0.012 & 0.60 & -0.043 & -0.47 \\
Rheinland-Pfalz or & $-0.038^{*}$ & -1.65 & -0.180 & -1.60 \\
Saarland & & & & -1.63 \\
Baden-Württemberg & 0.021 & 1.48 & -0.104 & -0.38 \\
Bayern & $0.023^{*}$ & 1.72 & -0.024 & \\
\hline \hline
\end{tabular}

Notes: Coefficients marked with two (one) asterisk(s) are significant at the 5 (10) per cent level. The occupation, industry, and sector of employment variables are taken from the most recently available of the most recently available of the corresponding three previous waves. People with no previous employment conceptually build an extra category for each of these three dummy variable groups. As a consequence, this variable appears in each group of the occupation, industry, and sector of employment variables for the transformation of the coefficients as described in Appendix A., although it only appears once in the estimation. As mentioned in the text and Appendix A., the reference person is the 1992 Sample Mean $\overline{\mathbf{x}}_{t}$ also for the year 1998.

Source: GSOEP; own calculations. 